\title{
Advances in the diagnosis and management of lymphoma
}

This article was published in the following Dove Press journal:

Blood and Lymphatic Cancer:Targets and Therapy

8 February 2012

Number of times this article has been viewed

\author{
Zachary H Word' \\ Matthew J Matasar ${ }^{1,2}$ \\ 'Lymphoma Service, Department of \\ Medicine, Memorial Sloan-Kettering \\ Cancer Center, ${ }^{2}$ Department of \\ Medicine, New York Presbyterian \\ Hospital, New York, NY, USA
}

\begin{abstract}
The lymphomas are a heterogeneous group of cancers that have played a prominent role in the history of oncology, being among the first cancers to respond to radiotherapy or systemic chemotherapy. Progressive improvement in the understanding of the biology and natural history of these diseases has led to changes in both classification and management. Because of the heterogeneity present among the lymphomas, accurate diagnosis and staging are essential prerequisites to their effective management. Lymphoma stage frequently informs treatment decisions, but in contrast with solid tumor malignancies carries limited prognostic value. This has led to the development of prognostic models in lymphoma, which use patient and disease characteristics to stratify patients by risk. Modern approaches to Hodgkin's lymphoma include chemotherapy only, combined-modality therapy with both chemotherapy and radiotherapy, and risk-adapted approaches that modify treatment based on initial response. Management of non-Hodgkin's lymphoma (NHL) varies widely depending upon histology. Use of rituximab, the anti-CD20 monoclonal antibody, is included in the management of most B cell lymphomas and has improved outcomes in these diseases. The $\mathrm{T}$ cell lymphomas are less common and generally less well understood than the B cell diseases, and their management has only recently become disease-specific. Though effective therapy is available for many types of lymphoma, relapse remains common in a number of subtypes, and management of relapsed and refractory disease remain research priorities.
\end{abstract}

Keywords: lymphoma, diagnosis, treatment

\section{Pathology and classification}

The lymphomas are characterized by neoplastic transformation of lymphocytes at specific stages in lymphocyte ontogeny. There are more than 50 distinct lymphomas in the current World Health Organization (WHO) classification system, existing along a broad spectrum with regards to pathophysiology, natural history, prognosis, and optimal management.

The first systematic attempts to classify the various lymphomas occurred in the 1930s, at which time their biology was poorly understood, and distinct clinicopathologic entities had yet to be well defined. Successive revisions in lymphoma classification schemes have occurred since then, and have paralleled developments in molecular biology and genetics, resulting in improvements in our ability to understand these diseases.

The Rappaport classification is generally considered the most important of the early systems, and was the first to incorporate prognosis. ${ }^{1}$ Like the other early systems, it relied entirely on morphologic appearance, predating such fundamental concepts in
Correspondence: Matthew J Matasar

Memorial Sloan-Kettering Cancer Center 1275 York Avenue, New York,

NY 10065, USA

Tel + I 2126398889

Fax +I 6464222291

Email matasarm@mskcc.org 
immunology as the distinction between $\mathrm{B}$ cells and $\mathrm{T}$ cells. As understanding of lymphoma biology progressed, the need for new classification schemes was met with numerous candidate systems, the relative merits of which were a subject of intense debate. Two dominant systems eventually emerged in the early 1970s. The Kiel classification was generally favored in Europe, and the Lukes and Collins classification, the first to distinguish B and T cell neoplasms, took hold in North America.

The absence of a single accepted classification system became an impediment to progress in the growing field of clinical research, leading Rosenberg, DeVita, and Kaplan, under the auspices of the National Cancer Institute, to bring experts together in 1982 in an attempt at unification. The goal went unmet, but the conference did result in the creation of an "international working formulation" to allow comparison across the various classification schemes. ${ }^{2}$ The international working formulation remained in use until the 1990 s, when a second attempt at unification resulted in the Revised European-American Lymphoma classification, first published in 1994 and later subsumed by the first WHO classification which includes all hematologic malignancies, both lymphoid and myeloid. ${ }^{3}$ The Revised EuropeanAmerican Lymphoma classification abandoned the attempt, common among earlier schemes, to privilege morphologic, immunophenotypic, or genetic information as the most important aspect of classification, but instead recognized that the importance of these factors varies across individual disease entities, and that clinical behavior varies within each entity. ${ }^{4}$ The most recent update of the WHO classification was released in 2008 (Table 1). ${ }^{5}$ It is broadly based on cell of origin, and initially distinguishes B cell, T cell, and natural killer cell disorders, with subsequent characterization based on stage of lymphocyte ontogeny. Key characteristic features of specific lymphoid neoplasms are listed in Table 2.

\section{Epidemiology}

It is expected that 66,360 cases of non-Hodgkin's lymphoma (NHL) and 8830 cases of Hodgkin's lymphoma will be diagnosed in the United States in 2011. ${ }^{6}$ The two most common types, diffuse large B cell lymphoma (DLBCL) and follicular lymphoma (FL), will account for about half of these. Other relatively common lymphomas include small lymphocytic lymphoma (SLL, chronic lymphocytic leukemia [CLL] type, $6 \%$ ), peripheral $\mathrm{T}$ cell lymphoma, not otherwise specified (PTCL-NOS, 6\%), mantle cell lymphoma (MCL, 6\%), and marginal zone lymphoma of mucosa-associated lymphoid tissue (MALT, 5\%). ${ }^{7,8}$
Table I World Health Organization classification scheme for lymphoma

\section{Mature B cell neoplasms}

Chronic lymphocytic leukemia/small lymphocytic lymphoma

B cell prolymphocytic leukemia

Splenic marginal zone lymphoma

Hairy cell leukemia

Lymphoplasmacytic lymphoma

Waldenström macroglobulinemia

Heavy chain diseases

$\alpha$ Heavy chain disease

$\gamma$ Heavy chain disease

$\mu$ Heavy chain disease

Plasma cell myeloma

Solitary plasmacytoma of bone

Extraosseous plasmacytoma

Extranodal marginal zone MALT lymphoma

Nodal marginal zone lymphoma

Follicular lymphoma

Primary cutaneous follicle center lymphoma

Mantle cell lymphoma

DLBCL, NOS

$T$ cell/histiocyte rich large B cell lymphoma

Primary DLBCL of the CNS

Primary cutaneous DLBCL, leg type

$D L B C L$ associated with chronic inflammation

Lymphomatoid granulomatosis

Primary mediastinal (thymic) large B cell lymphoma

Intravascular large B cell lymphoma

ALK-positive large B cell lymphoma

Plasmablastic lymphoma

Large B cell lymphoma arising in HHV8-associated multicentric

Castleman disease

Primary effusion lymphoma

Burkitt lymphoma

$B$ cell lymphoma, unclassifiable, with features intermediate between

diffuse large B cell lymphoma and Burkitt lymphoma

$B$ cell lymphoma, unclassifiable, with features intermediate between

diffuse large B cell lymphoma and classical Hodgkin's lymphoma

Hodgkin's lymphoma

Nodular lymphocyte predominant Hodgkin's lymphoma

Classical Hodgkin's lymphoma

Nodular sclerosis classical Hodgkin's lymphoma

Lymphocyte-rich classical Hodgkin's lymphoma

Mixed cellularity classical Hodgkin's lymphoma

Lymphocyte-depleted classical Hodgkin's lymphoma

Mature $\mathbf{T}$ cell neoplasms

T cell prolymphocytic leukemia

T cell large granular lymphocytic leukemia

Aggressive NK cell leukemia

Systemic EBV-positive T cell lymphoproliferative disease of childhood

Hydroa vacciniforme-like lymphoma

Adult $\mathrm{T}$ cell leukemia/lymphoma

Extranodal NK/T cell lymphoma, nasal type

Enteropathy-associated T cell lymphoma

Hepatosplenic $T$ cell lymphoma

Subcutaneous panniculitis-like T cell lymphoma

Mycosis fungoides/Sézary syndrome

(Continued) 
Table I (Continued)

Primary cutaneous CD30+ T cell lymphoproliferative disorders Lymphomatoid papulosis

Primary cutaneous anaplastic large cell lymphoma

Primary cutaneous $\gamma \delta$ T cell lymphoma

Peripheral T cell lymphoma, NOS

Angioimmunoblastic T cell lymphoma

Anaplastic large cell lymphoma, ALK-positive

Post-transplantation lymphoproliferative disorders

Early lesions

Plasmacytic hyperplasia

Infectious mononucleosis-like PTLD

Polymorphic PTLD

Monomorphic PTLD (B cell and T/NK cell types)

Classical Hodgkin's lymphoma type PTLD

(c) Adapted from Campo et al. ${ }^{241}$

Abbreviations: DLBCL, Diffuse large B-cell lymphoma; MALT, mucosa-associated lymphoid tissue; NK, natural killer; PTLD, post-transplantation lymphoproliferative disorder; CNS, central nervous system; EBV, Epstein-Barr virus; NOS, not otherwise specified.

Most cases of lymphoma are not associated with an identifiable epidemiological risk factor, but specific chronic infections, immunodeficiency states, or hereditary traits have been implicated in the pathogenesis for some. The Epstein-Barr virus has direct effects on host cell genomes that are implicated in the pathogenesis of various lymphomas, including a subset of Hodgkin's lymphoma, post-transplantation lymphoproliferative disorder (PTLD) in both solid organ and hematopoietic stem cell transplant recipients, and the endemic form of Burkitt lymphoma, seen mostly in Africa. ${ }^{9-11}$ Chronic stimulation of the immune system can be lymphomagenic, a phenomenon most clearly characterized in the cases of gastric MALT lymphoma due to infection with the bacteria Helicobacter pylori and splenic and extranodal marginal zone lymphomas associated with chronic hepatitis $\mathrm{C}$ infection; similarly, patients with common variable immunodeficiency and its consequent recurrent infections are at elevated risk for both MALT and aggressive lymphomas of both $\mathrm{B}$ cell and $\mathrm{T}$ cell origin. ${ }^{12-14}$

Autoimmune conditions, including rheumatoid arthritis, Sjögren's syndrome, and celiac sprue, are also associated with lymphoma, an effect thought to be mediated by chronic inflammation. ${ }^{15}$ The increased incidence of certain lymphomas in patients infected by the human immunodeficiency virus (HIV) with low CD4 counts and in patients treated with anti-tissue necrosis factor therapy for inflammatory bowel disease or the autoimmune arthritides suggests that immunosuppression confers an increased risk of lymphoma, although coexisting infections may play key roles. ${ }^{16,17}$ Certain industrial products, including pesticides and hair dyes prior to (but not after) 1980, have also been epidemiologically associated with lymphoma. ${ }^{18-20}$ The relative risk of all types of lymphoma is increased in patients with a family history of these diseases. ${ }^{21-24}$ However, because of the low baseline risk, the absolute risk of lymphoma remains small, even in patients with affected family members.

\section{Diagnosis}

Diagnosis of lymphoma is made primarily by pathologic evaluation of an appropriate tissue specimen, including morphologic, immunophenotypic, and cytogenetic evaluations as necessary, in the appropriate clinical setting. There are major differences in the management of individual lymphomas, making an accurate and specific diagnosis critical for appropriate patient care. A frequent practical issue that arises in the patient suspected to have lymphoma is the choice of biopsy technique and site. Surgical biopsy is preferred for initial diagnosis because the larger tissue sample obtained allows evaluation for processes that may heterogeneously involve the lymph node or extranodal mass, and performance of

Table 2 Characteristics of common lymphomas

\begin{tabular}{|c|c|c|}
\hline Subtype & Immunophenotype & Molecular lesions \\
\hline Classical Hodgkin's lymphoma & $\mathrm{CDI} 15+\mathrm{CD} 30+$ & Variable \\
\hline Nodular lymphocyte-predominant Hodgkin's lymphoma & CD20+ CDI5- CD30- & Variable \\
\hline Diffuse large B cell lymphoma & CD20+ & $\mathrm{BCL} 2, \mathrm{BCL} 6, \mathrm{C}-\mathrm{MYC}$ \\
\hline Follicular lymphoma & $\mathrm{CD} 20+\mathrm{CD} 10+\mathrm{CD} 5-$ & BCL2 \\
\hline Small lymphocytic lymphoma (chronic type) & $\mathrm{CD} 20+\mathrm{CD} 5+\mathrm{CD} 23+$ & $\mathrm{p} 53$, ATM,+12 \\
\hline Peripheral T cell lymphoma, unspecified & CD20- CD3+ & Variable \\
\hline Mantle cell lymphoma & $\mathrm{CD} 20+\mathrm{CD} 5+\mathrm{CD} 23-\mathrm{BCLI}+$ & Cyclin DI \\
\hline Marginal zone lymphoma & $\mathrm{CD} 20+\mathrm{CD} 5-\mathrm{CD} 23-$ & BCLIO, MALTI \\
\hline Primary mediastinal large B cell lymphoma & $\mathrm{CD} 20+\mathrm{CD} 30+$ & Variable \\
\hline Anaplastic large cell lymphoma, T/null & CD20- CD30+ CDI5- & $A L K$ \\
\hline Marginal zone lymphoma, nodal type & $\mathrm{CD} 20+\mathrm{CD} 5-\mathrm{CD} 23-$ & $+3,+18$ \\
\hline Burkitt lymphoma & CD20+ CDI0+ BCL6+ CD5- BCL2- TdT- & C-MYC \\
\hline
\end{tabular}


immunophenotypic, cytogenetic, and molecular analyses. ${ }^{25,26}$ Fine needle aspiration does not allow evaluation of the histologic architecture, and may provide insufficient tissue for comprehensive analysis including determination of biologic subtype. ${ }^{27}$ Fine needle aspiration can confirm relapsed disease in select situations, but even in this setting a core needle or surgical biopsy is preferred. ${ }^{28}$ Core needle biopsy may allow for an evaluation of nodal architecture, but samples a smaller amount of tissue than surgical biopsy, potentially missing a heterogeneous process and provides less material for comprehensive testing. Core needle biopsy is recommended for initial diagnosis only in clinical situations where a surgical biopsy cannot be readily obtained.

Despite standardized definitions in the WHO classification, approximately one fifth of lymphoma diagnoses will be revised upon review by an expert hematopathologist, with the rate varying among the individual types of lymphoma. ${ }^{29,30}$ Because appropriate management fundamentally depends on accurate pathologic diagnosis, expert pathology review is recommended and should be considered standard of care.

Medical imaging may be suggestive of lymphoma when the diagnosis is unknown and plays a key role in staging, but a definitive diagnosis of lymphoma and evaluation of the histologic subtype require pathological evaluation. Though not definitive, [18F]-fluoro-2-deoxyglucose positron emission tomography (FDG-PET) imaging can distinguish aggressive from indolent lymphomas based on standard uptake value measurement, and plays an important role in suggesting transformation of indolent to aggressive lymphoma (usually DLBCL). When transformation is suspected, PET can be used to select an appropriate biopsy site where the standard uptake value is highest and thus transformation is most likely to be present, but marked FDG avidity does not establish a diagnosis of transformation, and does not obviate the need for diagnostic biopsy. ${ }^{31}$

\section{Staging}

All patients with lymphoma should have a baseline evaluation including a physical examination, laboratory studies including complete blood count, comprehensive metabolic profile, and lactate dehydrogenase, and a computed tomography scan of the chest abdomen and pelvis. Bone marrow biopsy is also required for complete staging, but may be deferred until treatment is indicated in patients with indolent lymphoma and normal blood counts for whom watchful waiting would be recommended regardless of marrow involvement. The need for additional studies, such as further laboratory evaluation or functional imaging with FDG-PET, depends in part on the specific diagnosis and presentation. Lymphoma staging in the modern era is generally "clinical", meaning that it is based on the above-described studies, with or without further noninvasive evaluations to determine the extent of disease. "Pathologic" stage is based on one or more invasive staging procedures, such as staging laparoscopy, and is rarely performed in the modern era.

Stage is assigned according to the Ann Arbor staging system, as subsequently modified at the Cotswolds meeting in 1989 (Table 3). ${ }^{32}$ In contrast with most solid tumor malignancies, disease stage in lymphoma carries only limited prognostic significance. Stage IV disease will be found in

Table 3 Cotswolds modifications of Ann Arbor staging system

\begin{tabular}{|c|c|}
\hline Stage & Description \\
\hline Stage I & $\begin{array}{l}\text { Involvement of a single lymph node region or lymphoid structure (eg, spleen, thymus, Waldeyer's ring) or involvement } \\
\text { of a single extralymphatic site }\left(\mathrm{I}_{\mathrm{E}}\right)\end{array}$ \\
\hline Stage II & $\begin{array}{l}\text { Involvement of two or more lymph node regions (II) or localized contiguous involvement of one extranodal organ } \\
\text { and its regional lymph nodes }\left(\mathrm{II}_{\mathrm{E}}\right) \text { with all disease confined to one side of the diaphragm }\end{array}$ \\
\hline Stage III & $\begin{array}{l}\text { Involvement of lymph node regions on both sides of the diaphragm (III), which may also be accompanied by involvement } \\
\left.\text { of the spleen }\left(\mathrm{III}_{\mathrm{S}}\right) \text { or by localized contiguous involvement of one extranodal organ }\left(\mathrm{III}_{\mathrm{E}}\right) \text { or both (III } \mathrm{SE}_{\mathrm{SE}}\right)\end{array}$ \\
\hline Stage IV & $\begin{array}{l}\text { Disseminated (multifocal) involvement of one or more extranodal organs or tissues, with or without associated lymph } \\
\text { node involvement or isolated extralymphatic organ involvement with distant (non-regional) nodal involvement }\end{array}$ \\
\hline \multicolumn{2}{|c|}{ Designations applicable to any disease stage: } \\
\hline A & Absence of the " $B$ " symptoms described below \\
\hline B & $\begin{array}{l}\text { Fever (temperature }>38^{\circ} \mathrm{C} \text { ), drenching night sweats, unexplained loss of more than } 10 \% \text { of body weight } \\
\text { during the previous } 6 \text { months }\end{array}$ \\
\hline $\mathrm{X}$ & Bulky disease \\
\hline $\mathrm{E}$ & Extranodal involvement contiguous with a nodal site \\
\hline
\end{tabular}

Notes: Bulky disease has been defined as any lymph nodal mass $\geq 10 \mathrm{~cm}$ in greatest dimension, or a mediastinal mass with transverse diameter $\geq 1 / 3$ of the internal thoracic diameter at the level of the T5/6 intervertebral disk on posteroanterior chest radiograph. E lesions are distinguished from Stage IV disease in that they are contiguous with adjacent nodal disease and can be treated within the same radiation port.

(C) Adapted from Lister et al. ${ }^{32}$ 
many cases of indolent B cell NHL due to involvement of bone marrow. However, in the absence of other extranodal sites, bone marrow involvement carries limited prognostic significance, and evaluation of bone marrow is not universally required at the time of diagnosis unless therapy is planned or cytopenias are present.

\section{Prognostic models}

Because stage carries limited prognostic value for both Hodgkin's lymphoma and NHL, clinical prognostic models incorporating both patient and disease characteristics have been developed to define risk groups more accurately. In Hodgkin's lymphoma, several definitions of "favorable" and "unfavorable" early-stage disease (ie, stage I-II) have been developed by cooperative groups in an attempt to identify a subset of patients for whom treatment intensity can be safely reduced. The International Prognostic Score (Table 4) has been used in patients with advanced-stage disease (ie, stage III-IV). ${ }^{33-36}$ The first prognostic model to be developed in NHL was the International Prognostic Index (IPI), which was initially validated in a cohort of patients with aggressive lymphomas, primarily diffuse large B cell lymphoma, but was also applied to other lymphoma subtypes. ${ }^{37}$ In follicular lymphoma, the most common indolent lymphoma, the IPI score is of some prognostic value, but in a majority of patients it is classified as higher risk owing to bone marrow involvement and resultant stage IV disease. This observation prompted development of a model more capable of discriminating cases into risk strata,

Table 4 International prognostic scoring system for Hodgkin's lymphoma

\begin{tabular}{|c|c|c|}
\hline \multicolumn{3}{|l|}{ Risk factors } \\
\hline \multicolumn{3}{|l|}{ Serum albumin, $<4 \mathrm{~g} / \mathrm{dL}$} \\
\hline \multicolumn{3}{|l|}{ Hemoglobin, $<10.5 \mathrm{~g} / \mathrm{dL}$} \\
\hline \multicolumn{3}{|l|}{ Male gender } \\
\hline \multicolumn{3}{|l|}{ Stage IV disease } \\
\hline \multicolumn{3}{|l|}{ Age $\geq 45$ years } \\
\hline \multicolumn{3}{|c|}{ White blood cell count, $\geq 15,000 / \mathrm{mm}^{3}$} \\
\hline \multicolumn{3}{|c|}{ Lymphocyte count, $<600 / \mathrm{mm}^{3}$ or $<8 \%$ of white blood cells } \\
\hline \multicolumn{3}{|l|}{ Outcomes } \\
\hline Number of factors & $\begin{array}{l}5 \text {-year progression-free } \\
\text { survival }\end{array}$ & $\begin{array}{l}5 \text {-year overall } \\
\text { survival }\end{array}$ \\
\hline 0 & 84 & 89 \\
\hline I & 77 & 90 \\
\hline 2 & 67 & 81 \\
\hline 3 & 60 & 78 \\
\hline 4 & 51 & 61 \\
\hline$\geq 5$ & 42 & 56 \\
\hline
\end{tabular}

○ Adapted from Hasenclever and Diehl. ${ }^{33}$ ie, the Follicular Lymphoma International Prognostic Index (FLIPI) score, developed in what is now an older treatment era, and offered such discriminatory power. ${ }^{38}$ As treatment and prognosis have evolved, most notably with the use of rituximab, a monoclonal antibody against CD20, it was postulated that risk modeling may have changed as well. In the case of follicular lymphoma, an evaluation of prognostic factors for progression-free survival in the rituximab era resulted in development of the FLIPI-2, which identifies groups with 3-year progression-free survival ranging from $91 \%$ to $51 \%{ }^{39}$ Significant heterogeneity of outcome continues to exist in the various risk groups identified by both FLIPI and FLIPI-2, however, and treatment decisions should not be based upon these scores.

Risk models for other individual types of NHL have subsequently been developed, including the Mantle Cell Lymphoma International Prognostic Index (MIPI) and Prognostic Index for Peripheral T cell Lymphoma. ${ }^{40,41}$ Proliferative rate, as measured by Ki-67 staining, has emerged as an important prognostic variable in both of these lymphoma subtypes, and has been incorporated into a combined form of the MIPI and a modified Prognostic Index for Peripheral T cell Lymphoma. ${ }^{42}$ Prognostic indices have also been developed for specific clinical scenarios, such as the age-adjusted IPI, the stage-adjusted IPI, and the secondline age-adjusted IPI. ${ }^{37,43,44}$

The prognosis of lymphoma subtypes of course changes with the effectiveness of available treatments. In Hodgkin's lymphoma, therapy has been successfully adapted to initial risk such that the initial International Prognostic Score is of less prognostic value. ${ }^{45}$ This has been less true in NHL, but changes in treatment standards, including the addition of the monoclonal antibody, rituximab, have still altered outcomes and required revision of prognostic models. ${ }^{46}$ Furthermore, progress in the molecular characterization of the individual lymphomas and their microenvironments has yielded new prognostic variables that will likely be incorporated into risk models in the future.

\section{Hodgkin's lymphoma}

Hodgkin's lymphoma, previously called Hodgkin's disease, has now been shown to result from malignant transformation of a germinal center or post-germinal center B cell. The Reed-Sternberg cell was initially described in 1898, but it was not until 1994 that Küppers et al demonstrated it to be of lymphoid origin. ${ }^{47}$ Representing about 10\%-12\% of all lymphomas, Hodgkin's lymphoma is expected to affect 8830 patients in the US in 2011, and to result in 
1300 deaths. $^{6}$ There is a slight male predominance in the incidence (1.4:1) and a bimodal age distribution in Western countries. The major peak in incidence occurs among patients in their 20s, with a smaller and broader peak over age 50 years. ${ }^{48}$ The Epstein-Barr virus is detectable in approximately $40 \%$ of Hodgkin's lymphoma cases, and is thought to be directly involved in transformation. ${ }^{49}$ Infectious mononucleosis, which is caused by Epstein-Barr virus, increases the risk of Hodgkin's lymphoma among young adults. ${ }^{9}$ Patients infected with HIV also have an increased risk of Hodgkin's lymphoma. In contrast with other HIVassociated malignancies, Hodgkin's lymphoma is not an acquired immune deficiency syndrome (AIDS)-defining condition, and is not prevented by controlling HIV infection with antiretroviral therapy. ${ }^{17}$

Classical Hodgkin's lymphoma subsumes the morphologic subtypes of nodular sclerosis, ie, mixed cellularity, lymphocyte-rich, and lymphocyte-depleted. Recent studies have suggested that nodular sclerosing Hodgkin's lymphoma, the most common subtype in Western countries, may be somewhat distinct from the others. ${ }^{50}$ Nodular sclerosis Hodgkin's lymphoma has a female predominance, is more common among younger patients than older ones, and is more likely than other subtypes to present with a large mediastinal mass. Immunophenotypic and cytogenetic characteristics differ between nodular sclerosing Hodgkin's lymphoma and other subtypes of classical Hodgkin's lymphoma, but intriguingly, the former shares many molecular and clinical characteristics with primary mediastinal large B cell lymphoma, a subtype of DLBCL. Nonetheless, all of the subtypes of classical Hodgkin's lymphoma, including nodular sclerosing Hodgkin's lymphoma, routinely share a single treatment paradigm and all have a similar prognosis except the uncommon and prognostically unfavorable lymphocyte-depleted variant. ${ }^{51}$

Nodular lymphocyte predominant Hodgkin's lymphoma (NLPHL) is a clinical entity distinct from classical Hodgkin's lymphoma and recognized as such by the WHO. It often has an indolent relapsing course that in some ways bears closer resemblance to indolent NHL, and its optimal treatment often diverges from standard Hodgkin's lymphoma therapy.

\section{Classical Hodgkin's lymphoma Clinical presentation}

Classical Hodgkin's lymphoma is characterized by a unique pattern of contiguous and predictable spread to successive, adjacent lymph node groups. ${ }^{50}$ The most common sites of disease are the mediastinum and bilateral base of the neck.
Involvement of the axilla is uncommon without involvement of the ipsilateral cervical or supraclavicular region, as is involvement of either hilum without mediastinal disease and involvement of abdominal (subdiaphragmatic) lymph nodes or spleen without hilar disease. ${ }^{52}$ Extranodal spread, which occurs via vascular invasion and hematogenous dissemination, is usually a late event, with the most common sites being bone, bone marrow, lung, and liver. Involvement of the central nervous system (CNS) or leptomeninges, even with multiply relapsed disease, is extremely rare.

Many patients initially present with nonspecific symptoms including lymphadenopathy, fever, and malaise. Peripheral lymphadenopathy is present in most patients at diagnosis; it is found in the cervical or supraclavicular areas in $60 \%-80 \%$ of cases, and in the axillary region in approximately $10 \%-20 \%$. Clinical distinction between the lymphadenopathy seen in lymphoma from that seen in infectious processes can be difficult, but the former tends to be nontender on palpation, and more often involves the base of the neck and supraclavicular areas rather than the upper neck. Mediastinal lymph node masses, which can be large, are present in 50\%-60\% of cases, and may be discovered incidentally on imaging in asymptomatic patients, or become symptomatic with respiratory complaints or chest pain. Subdiaphragmatic presentations are uncommon, representing $3 \%-7 \%$ of cases, and are associated with mixed cellularity histology, advanced age, and poorer prognosis. ${ }^{53-55}$ Rarely, the presenting symptoms may be accounted for by a paraneoplastic syndrome such as cerebellar degeneration, which is more common in men, and may arise in the context of both early-stage and advanced-stage disease. ${ }^{56}$

Systemic "B" symptoms, which occur in about one quarter of newly diagnosed patients, are more common in the setting of advanced stage disease, and confer a worse prognosis independent of stage. Fatigue is common, but does not have prognostic relevance. Generalized pruritus is common and associated with inferior outcome when severe. ${ }^{57,58}$ A syndrome of pain in involved lymph nodes immediately after ingestion of alcohol is uncommon but pathognomonic for Hodgkin's lymphoma. ${ }^{59}$

\section{Staging}

Hodgkin's lymphoma is staged according the Cotswolds modification of the Ann Arbor staging system as described above. It is categorized as "early" for nonbulky stage I-II or "advanced" for stage III-IV, and bulky disease of any stage. Both chest $\mathrm{x}$-ray and computed tomography (CT) scans of the chest, abdomen, and pelvis should be performed in order to evaluate 
disease bulk. Bone marrow biopsy should be performed in all patients except those with stage IA disease. FDG-PET is now recommended for routine use in pretreatment evaluation, and should be considered in all patients. ${ }^{26}$ For those thought to have early-stage disease, additional sites of involvement may be found and result in a change of stage. Among patients already known to have advanced-stage disease, a baseline FDG-PET may be useful for comparison with subsequent restaging scans. Interim FDG-PET, usually performed after two cycles of therapy and post-treatment FDG-PET are both predictive of ultimate outcome. ${ }^{60-63}$ Ongoing studies of riskadapted approaches will further elucidate the role of interim PET in guiding treatment modifications.

\section{Management}

Improvements in chemotherapy, radiation therapy, and salvage techniques have made Hodgkin's lymphoma highly curable, with approximately $85 \%$ of patients achieving long-term disease-free survival. Optimal management of Hodgkin's lymphoma depends on the stage of disease (early or advanced), prognostic factors, risk of toxicity, and response to therapy.

Early-stage Hodgkin's lymphoma was once managed with extended field radiotherapy, but combination chemotherapy with subsequent radiation (ie, combined-modality therapy) results in improved failure-free survival, and is now standard of care ${ }^{64-67}$ However, toxic side effects of such therapy are substantial, with long-term follow-up studies demonstrating that by 25 years after treatment, toxicity overtakes relapse as the most common cause of death (Table 5) ${ }^{6}{ }^{6}$ Strategies to improve long-term outcomes by reducing toxicity without compromising disease control have become a focus of research over the course of recent decades. The most serious chemotherapy side effect seen with the older, alkylator-based chemotherapy regimens such as MOPP (mechlorethamine, vincristine, procarbazine, prednisone) was the predisposition to acute leukemia. Investigations in the 1970s and 1980s demonstrated that anthracycline-based regimens such as ABVD (doxorubicin, bleomycin, vinblastine, dacarbazine) resulted in improved disease control with decreased toxicity, and supplanted alkylator-based therapy as the standard of care. ${ }^{69-71}$ Though the risk of leukemia is not eliminated with anthracycline-based therapy, it has been reduced. The risk of radiation-induced toxicity has also been mitigated, but not eliminated, by modern radiotherapy techniques which limit the radiation exposure to non-target tissues. ${ }^{72}$

Similar but nonidentical prognostic factors (Table 6) have been used by various investigators to define a "favorable-risk"
Table 5 Toxicities associated with treatment of Hodgkin's lymphoma

\begin{tabular}{l} 
Acute toxicity \\
Alopecia \\
Cytopenias \\
Mucositis \\
Nausea/vomiting \\
Neuropathy (vinca alkaloids) \\
Pneumonitis (bleomycin, radiotherapy) \\
Second malignancy \\
Acute leukemia (chemotherapy) \\
Breast (radiotherapy) \\
Gastric \\
Lung (radiotherapy) \\
Melanoma \\
Non-Hodgkin's lymphoma \\
Sarcoma (radiotherapy) \\
Thyroid (radiotherapy) \\
Late cardiovascular toxicity \\
Accelerated atherosclerosis \\
Nonischemic cardiomyopathy \\
Pericardial fibrosis (radiotherapy) \\
Endocrine toxicities \\
Hypothyroidism (radiotherapy) \\
Infertility \\
\hline
\end{tabular}

subset of patients with early-stage Hodgkin's lymphoma and a low likelihood of relapse. This group has a failure-free survival of approximately $90 \%$ after combined-modality therapy with overall survival $>95 \%$ due to the availability of effective salvage therapy for relapsing patients. Given these excellent outcomes, and the long-term risks of combinedmodality therapy, research has started to focus on reducing treatment intensity. The German Hodgkin Study Group has shown that two cycles of ABVD chemotherapy followed by 20 Gy of involved field radiation (IFRT) is as effective for favorable risk patients as four cycles of chemotherapy and 30 Gy of IFRT, which was previously the standard of care, and remains so for patients with "unfavorable" earlystage Hodgkin's lymphoma. ${ }^{73}$ However, even reduced doses of radiation are likely to engender long-term toxicity, and chemotherapy-only programs have also been explored. ${ }^{74}$ A response-adapted chemotherapy-only regimen evaluated by the National Cancer Institute of Canada involved reevaluation of disease status after two initial cycles of ABVD chemotherapy with a CT scan; patients who had a complete response or unconfirmed complete response by $\mathrm{CT}$ criteria went on to receive two more cycles of ABVD, and those with lesser responses went on to receive four additional cycles for a total of six. Patients who achieved at least an unconfirmed complete response after two cycles of therapy had outstanding rates of cure, suggesting that the reduction 
Table 6 Risk factors for unfavorable early-stage Hodgkin's lymphoma

\begin{tabular}{lll}
\hline Risk factor & Definition & Source \\
\hline Bulky disease & $>10 \mathrm{~cm}$, or mediastinal mass $>$ I/3 thoracic diameter & GHSG, NCIC, NTI, DFCl \\
& Mediastinal mass $>$ I/3 thoracic diameter & EORTC \\
Age & $\geq 40$ (EORTC also distinguishes $\geq 50)$ & NCIC, EORTC \\
ESR & $>50$ in asymptomatic patient; $>30$ in patient with B symptoms & GHSG, EORTC \\
& $>50$ or presence of B symptoms & NCIC \\
Histology & Mixed cellularity or lymphocyte depleted & NCIC \\
Extranodal disease & Any extranodal site & GSHG, NTI \\
Nodal sites & $\geq 3$ nodal sites & GSHG, EORTC \\
& $\geq 4$ nodal sites & NCIC, EORTC \\
Sex & Male & EORTC \\
Other & Intra-abdominal disease & NCIC \\
& Pulmonary hilar involvement & NTI
\end{tabular}

(C) Adapted from Armitage. ${ }^{242}$

Abbreviations: ESR, erythrocyte sedimentation rate; GHSG, German Hodgkin Study Group; NCIC, National Cancer Institute of Canada and Eastern Cooperative Oncology Group; NTI, National Tumor Institute, Milan; DFCI, Dana-Farber Cancer Institute; EORTC, European Organization for Research on the Treatment of Cancer.

in chemotherapy duration did not compromise eradication of their lymphoma. However, overall, this chemotherapy-only strategy was associated with slightly inferior disease control compared with combined-modality therapy (although overall survival was the same between the two treatment arms), which highlights the need to weigh toxicity against the risk of relapse. ${ }^{66}$ Among women under the age of 20 receiving IFRT involving the breast, the risks of breast cancer are as high as those among BRCA1 carriers, and are still significantly elevated for women aged $20-30$ years. It is possible that chemotherapy-only treatment with ABVD may be associated with a small increased risk of relapse, although this has not been definitively established; regardless, the decision between combined-modality therapy and chemotherapy-only treatment must be individualized, weighing risks of relapse against risks of late toxicity.

Advanced-stage Hodgkin's lymphoma is treated with systemically administered combination chemotherapy, with radiation therapy often used at sites of bulky disease, if such are present. As described above, the preferred regimen has evolved over time from alkylator-based to anthracyclinebased regimens. ABVD given every 2 weeks for a total of 12 treatments (six cycles) is the best studied and most commonly used. The Stanford V regimen, which used a shorter course of chemotherapy with increased radiation, is also effective. ${ }^{75}$ Recent comparisons of Stanford V and ABVD have been reported in both advanced-stage Hodgkin's lymphoma and bulky early-stage Hodgkin's lymphoma. These have shown equivalent disease control overall, although Stanford V may be inferior for moderate-risk or high-risk advanced-stage Hodgkin's lymphoma. ${ }^{76,77}$ While ABVD remains the standard of care in the US, Stanford V may be useful in select cases where its lower doses of anthracycline and bleomycin and shorter duration of treatment are particularly advantageous.

The prognostic model used for advanced-stage Hodgkin's lymphoma is the International Prognostic Score which identifies age older than 45 years, male gender, serum albumin $<4$, hemoglobin $<10.5$, white blood cell count $>15,000$, lymphopenia (absolute lymphocyte count $<600$ or lymphocytes representing $<8 \%$ of differential), and stage IV disease as adverse prognostic features. ${ }^{33}$ The International Prognostic Score identifies a group of "unfavorable-risk" advanced-stage Hodgkin's lymphoma patients with a $30 \%-40 \%$ risk of relapse following standard ABVD therapy, which has prompted evaluation of more intensive regimens for use in this group. The German Hodgkin Study Group's escalated BEACOPP regimen (bleomycin, etoposide, doxorubicin, cyclophosphamide, vincristine, procarbazine, prednisone) improves tumor control in this group, and in the initial report also improved overall survival. ${ }^{78}$ However, a subsequent study compared ABVD and escalated BEACOPP, with planned salvage therapy using high-dose chemotherapy and autologous stem cell rescue (HDT/ASCR) in all relapsed patients, and showed no survival advantage for the more intensive regimen, despite improved initial tumor control. ${ }^{79}$ The escalated BEACOPP regimen has increased toxicity, including a higher rate of infertility and secondary leukemia. At the present time, it is unclear which patients benefit sufficiently from the intensified regimen to justify the increased toxicity, although many investigators are pursuing risk-adapted strategies that either escalate from ABVD to BEACOPP in individuals failing to respond early in the course of therapy, or de-escalate from BEACOPP to ABVD in patients who do respond. 
Salvage chemotherapy is administered in patients who relapse after an initial remission, or fail to respond to initial therapy. If a response to salvage therapy is obtained, and the disease is demonstrated to be "chemosensitive", consolidation with HDT/ASCR is undertaken, and results in long-term remission in $45 \%-60 \%$ of patients. ${ }^{80-86}$ Allogeneic stem cell transplantation, usually following reduced intensity conditioning, takes advantage of an immunologic response by donor immune cells against the lymphoma, and can also result in durable remission. Its role is less well defined, and it is frequently deferred until after failure of HDT/ASCR. ${ }^{87,88}$ Brentuximab vedotin, a new agent which consists, molecularly, of the cytotoxic agent monomethyl auristatin E linked to a monoclonal antibody-directed against the CD30 antigen present in most cases of Hodgkin's lymphoma, has also shown excellent single-agent activity among patients with relapsed Hodgkin's lymphoma following HDT/ASCR or ineligible for transplantation, and is the first drug approved by the US Food and Drug Administration for the treatment of relapsed Hodgkin's lymphoma. ${ }^{89}$ Its use as maintenance therapy or incorporated into combination therapy regimens is the subject of ongoing investigation. Many other classes of agents, including histone deacetylase inhibitors such as panobinostat, immunomodulatory drugs such as lenalidomide, inhibitors of the mammalian target of rapamycin (mTOR) such as everolimus, cytotoxic drugs such as bendamustine, and others are in clinical development for the management of Hodgkin's lymphoma, and treatment of relapsed disease remains a high priority for clinical trials worldwide.

\section{Nodular lymphocyte-predominant Hodgkin's lymphoma}

NLPHL is a distinct clinicopathologic entity with a natural history characterized by an indolent but relapsing course and a treatment paradigm distinct for that used in classical Hodgkin's lymphoma. It most commonly affects males, with a bimodal age distribution peaking in childhood and the fourth decade of life..$^{90}$ The pathologic hallmark of NLPHL is the lymphocytic and histiocytic cell, which is a Reed-Sternberg variant derived from a germinal center B lymphocyte origin. ${ }^{91,92}$ Patients typically present with peripheral adenopathy, and a majority have early-stage disease at the time of diagnosis. In contrast with classical Hodgkin's lymphoma, mediastinal masses are uncommon, and lymph node stations are less likely to become involved in a sequential and orderly progression. ${ }^{52,93}$ Clinical staging of NLPHL follows the same procedure as for classical Hodgkin's lymphoma. FDG-PET has not been validated in NLPHL, and may be confounded by the potential coexistence of a benign lymph node condition called progressive transformation of germinal centers, which may be FDG-PET-avid. ${ }^{94}$ Bone marrow is rarely involved and need not be evaluated at diagnosis unless peripheral counts are abnormal.

Treatment of NLPHL with classical Hodgkin's lymphoma regimens, as was previously common, results in high response rates, but frequent relapses and has largely been abandoned in favor of more conservative strategies among early-stage patients. IFRT is appropriate for patients whose disease may be contained within a single radiation port, and may be curative. Combination chemotherapy is used for advancedstage disease. Randomized trials are not available to guide treatment choice, but nonrandomized data have indicated that the combination of rituximab, cyclophosphamide, doxorubicin, vincristine, and prednisone (R-CHOP) may perform better than other regimens. ${ }^{95}$ Unlike the ReedSternberg cells of classical Hodgkin's lymphoma, the lymphocytic and histiocytic cells of NLPHL do express the CD20 antigen, rendering them susceptible to targeting with rituximab, a monoclonal antibody. Due to its low toxicity profile, single-agent rituximab has also been evaluated and produces high response rates, but short durations of response. The ultimate role of this agent in therapy for NLPHL is still being evaluated. ${ }^{41,96,97}$ Given the indolent relapsing nature of NLPHL and the young age of affected patients, repeated bouts of therapy are employed over the natural history of the disease. Recent recognition of the cumulative toxicity associated with such treatment, including secondary malignancies and heart disease, has prompted attempts to limit therapy when possible..$^{93,98}$

\section{Non-Hodgkin's lymphoma Diffuse large B cell lymphoma}

The term DLBCL is applied to a group of clinically aggressive disorders that collectively account for more than $30 \%$ of all new lymphoma diagnoses. ${ }^{7}$ DLBCL consists of several morphologic patterns, and there are multiple clinical subtypes recognized by the WHO. Individual entities in this group have similar clinical behavior, and have similar treatment paradigms. The most common is DLBCL-NOS; other clinical subtypes include primary mediastinal large B cell lymphoma, T cell/histiocyte-rich large B cell lymphoma, primary DLBCL of the CNS, primary cutaneous DLBCL, leg type, primary effusion lymphoma, and intravascular large B cell lymphoma.

More recently, distinct molecular subtypes of DLBCLNOS have been recognized based on the results of gene 
expression profiling, which segregates most cases into one of three generally accepted phenotypic variants, ie, activated B cell-like, germinal center B cell-like, and primary mediastinal large B cell lymphomas. ${ }^{99-104}$ These types differ in their molecular pathogenesis, prognosis, and response to treatment. This distinction is yet to change management routinely, however, and is not currently recognized by the WHO classification owing to the technical difficulty of classifying individual cases. Comprehensive gene expression profiling is not practical for routine use, leading to a search for alternative techniques for phenotypic classification. Immunohistochemistry-based algorithms, which are less expensive and more widely available, have been developed, but their accuracy has been questioned and a widely accepted tool does not yet exist. ${ }^{103-106}$

\section{Clinical presentation}

DLBCL usually presents symptomatically in the form of a palpable peripheral mass, symptoms resulting from compression of adjacent structures caused by central adenopathy, or symptoms arising from extranodal sites of disease. Fewer than half of patients present with early-stage disease, and about one third will have extranodal sites of involvement. ${ }^{8,107}$ Systemic symptoms including fatigue and pruritus are present in a majority of cases, and approximately $30 \%$ will meet specific criteria for "B" symptoms. Lymphoma can arise in extranodal sites, most commonly the gastrointestinal tract, and associated adenopathy may be minimal in such cases. Patients with primary extranodal disease are more likely to present with early-stage disease. Involvement of extranodal tissues also occurs in primary nodal lymphomas, where it is a late event associated with advanced-stage disease and widespread lymphadenopathy. In this setting, the most commonly involved sites are the bone and bone marrow, liver, lung, and kidney. ${ }^{108}$

Some cases of DLBCL occur as a transformation of a previously existing indolent lymphoma, which may or may not have been diagnosed. When an undiagnosed indolent lymphoma presents in a transformed state, it is termed "de novo" transformation and identified by the presence of both indolent and aggressive components within a pathologic specimen. The risk of transformation exists in all indolent lymphomas, but is best studied in FL, where the lifetime risk of transformation is estimated to be $20 \%-50 \%{ }^{109-111}$ Patients with indolent lymphoma who live $>15$ years without transformation are unlikely to experience it subsequently. Transformation of FL to DLBCL is thought to result from additional mutations occurring in a single cell in the FL clone, resulting in clonally related coexisting DLBCL and FL. ${ }^{112}$ In contrast, transformation of CLL/SLL to DLBCL (the so-called Richter syndrome), results in a DLBCL clone distinct from the underlying indolent disease in a significant minority of cases. ${ }^{113}$ Transformed DLBCL is treated in a manner identical to that used for DLBCL without antecedent indolent lymphoma, but the prognosis is worse in transformed disease. Since indolent lymphomas are typically not curable with conventional therapy, they are expected to recur even in patients cured of the transformed component of their disease.

\section{Staging}

In addition to routine clinical staging, body imaging with CT and FDG-PET and bone marrow biopsy are performed in the initial evaluation of DLBCL. Lumbar puncture with intrathecal instillation of chemotherapy is indicated for patients with increased risk of CNS involvement based on clinical features. Most experts recommend prophylactic administration of chemotherapy, most typically four to six doses of methotrexate or cytarabine, even in the absence of positive cerebrospinal fluid cytology for lymphomatous involvement. The characteristics that prompt the use of prophylaxis include site of origin, with involvement of the testis, paranasal sinuses, nasopharynx, breast, or bone marrow; multiple extranodal sites of disease in the presence of an elevated lactate dehydrogenase, regardless of the sites involved, or high-risk IPI. ${ }^{114-119}$

\section{Management}

A majority of patients with DLBCL can be cured with aggressive chemotherapy or combined-modality therapy. The CHOP regimen (cyclophosphamide, doxorubicin, vincristine, prednisone) was first described for use in lymphoma in $1976 .{ }^{120}$ The National High-Priority Lymphoma Study, reported in 1993, compared CHOP with several more intensive alternatives, and found it to produce equivalent results with less toxicity and lower cost. ${ }^{121} \mathrm{CHOP}$ was established as the worldwide standard of care and remained so until it was improved by the addition of rituximab in the early 2000s. R-CHOP has been evaluated in four large randomized clinical trials which have demonstrated its superiority to chemotherapy alone, and established it as the current standard of care. ${ }^{122-125}$ The French Groupe d'Etude des Lymphomes de l'Adulte (GELA) study, as an example, compared R-CHOP with CHOP in patients aged $>60$ years and found 5-year progression-free survival of 54\% and $30 \%$ in the two groups, respectively. ${ }^{126}$ The addition of rituximab is beneficial in both older and younger patients, and across all 
IPI risk scores. Patients with advanced stage disease typically receive six cycles of R-CHOP, though eight cycles, as was used in the GELA study, may also be given. Nonbulky earlystage disease can, alternatively, be treated with abbreviated R-CHOP chemoimmunotherapy (3-4 cycles) followed by IFRT. ${ }^{123,127}$ Bulky disease of any stage is usually treated with a full 6-8 cycles of R-CHOP with or without IFRT.

Efforts to improve upon R-CHOP continue, with various approaches undergoing evaluation. Dose-dense therapy, with decreased intervals between treatment cycles from 21 to 14 days, enabled by routine growth factor support and prophylactic antibiotics, offers theoretical benefit according to the Norton-Simon model of tumor growth. ${ }^{128}$ Initial reports of this strategy showed improved survival with CHOP every 2 weeks compared with the standard 3 weeks. ${ }^{129}$ However, studies of dose-dense R-CHOP have shown 2-week cycles to be as safe as 3-week cycles, but have failed to demonstrate improvement in outcomes. ${ }^{130,131}$ The dose-adjusted EPOCH regimen, composed of many of the same drugs as CHOP, is administered by continuous infusion rather than bolus dosing, based on the hypothesis that this may overcome the poor prognosis associated with high proliferative rate tumors, and P glycoprotein-mediated drug resistance. ${ }^{132,133}$ The regimen is promising, and, though trials have not specifically targeted these groups, some hypothesize that it may have particular benefit for highly aggressive entities, including the "double hit" lymphomas which have abnormalities involving the myc gene in addition to another recurrent genetic abnormality, such as bcl-2 overexpression, and lymphomas diagnosed under the WHO classification as "B cell lymphoma, unclassifiable, with features intermediate between DLBCL and Burkitt lymphoma". ${ }^{134}$ A randomized clinical trial comparing R-dose-adjusted EPOCH regimen with R-CHOP is currently being conducted by the Alliance for Clinical Trials in Oncology (formerly known as the Cancer and Leukemia Group B). A third strategy posits that improved outcomes can be achieved with the use of non-crossreactive sequential initial therapy, in which the initial course of R-CHOP is abbreviated and a regimen such as ICE (ifosfamide, carboplatin, etoposide), which has traditionally been used in the relapsed setting, is used instead to complete initial therapy. This approach has demonstrated excellent results in higher-risk patients, but has not yet been directly compared with R-CHOP alone. ${ }^{135}$

Management of patients with disease that is refractory to initial therapy, or relapses following an initial response diverges based upon the potential eligibility of the patient for intensive treatment. Treatment of the transplant-eligible patient involves administration of short-course, high-potency, second-line chemotherapy in an attempt to achieve prompt remission, which is then consolidated with HDT/ASCR. This approach offers a second opportunity for cure in patients with relapsed or refractory DLBCL, but as outcomes with first-line therapy have improved in the rituximab era, outcomes for second-line therapy have worsened. ${ }^{136,137}$ Patients ineligible for HDT/ASCR are managed with systemic therapy and/or radiotherapy, with a goal of disease control; only a small percentage of such patients will be cured by routine secondline therapy, eg, rituximab, cyclophosphamide, etoposide, procarbazine, prednisone (R-CEPP). Allogeneic stem cell transplant may offer a final chance of cure for eligible patients relapsing after or ineligible for HDT/ASCR, though the ability to achieve disease control adequate to justify such treatment is often poor. ${ }^{138}$

\section{Primary mediastinal large B cell lymphoma}

Primary mediastinal large B cell lymphoma (PMLBCL) is a subtype of DLBCL with distinct biological and clinical features. Gene expression profiling studies have shown genetic similarity between PMLBCL and Hodgkin's lymphoma. ${ }^{139,140}$ The clinical features of this subtype are also similar to nodular sclerosis Hodgkin's lymphoma, with a relatively young median age at diagnosis, a female predominance, and a typical presentation with an anterior mediastinal mass that causes radiographic compression of the superior vena cava in $80 \%$ of cases and clinical superior vena cava syndrome in $50 \%{ }^{141}$ It is most commonly managed like other subtypes of DLBCL, with R-CHOP chemoimmunotherapy and radiation. The strategy of sequential R-CHOP and ICE appears particularly promising for PMLBCL, however, and may relieve the need for mediastinal radiotherapy. ${ }^{142-145}$

\section{Primary diffuse large B cell lymphoma of the CNS}

Categorized as a subtype of DLBCL-NOS by the WHO, primary diffuse large B-cell lymphoma of the CNS (PLCNS) represents a specific extranodal presentation with distinct management implications. It may involve the brain parenchyma, spinal cord, cerebrospinal fluid, meninges (except the dura), or eyes, and all should be evaluated in patients with the diagnosis. ${ }^{146}$ It may involve sites outside the CNS, and body imaging with CT or FDG-PET as well as bone marrow biopsy is required for complete staging, as for other types of DLBCL. PLCNS is associated with immunodeficiency, particularly infection with HIV, 
but occurs in immunocompetent patients. Presentation is usually with focal neurologic deficits, personality change, or visual symptoms. ${ }^{147}$ The IPI has not been found to predict risk in PLCNS, but a prognostic model defined by the International Extranodal Lymphoma Study Group uses age, performance status, serum lactate dehydrogenase, involvement of deep brain structures, and cerebrospinal fluid protein level to identify three risk groups with 2-year overall survival ranging from $15 \%$ to $80 \% .{ }^{148}$ Treatment with regimens such as R-CHOP, as used for DLBCL of other sites, is limited by poor penetration of the drugs into the CNS. Combined-modality therapy with a high-dose methotrexate-based systemic chemotherapy regimen and whole brain radiation therapy are the mainstays of therapy. Whole brain radiation therapy is associated with a high rate of neurologic toxicity, particularly in patients over the age of 60 years when chemotherapy-only regimens are more often employed. Consolidation of initial responses with HDT/ASCR has shown good results in a nonrandomized investigation. ${ }^{149}$

\section{Intravascular large B cell lymphoma}

Intravascular large B cell lymphoma is a rare subtype of DLBCL, characterized by neoplastic lymphocytes localized within the lumina of small blood vessels, usually capillaries, with minimal or no extravascular extension. Nodal disease is typically absent, and additional extranodal sites beyond the intravascular component are relatively common, and may include the CNS. Two forms have been identified which differ in their clinical features and geographic distributions. In Western countries, patients often have CNS or cutaneous involvement, and in Asia they tend to have bone marrow involvement, hemophagocytic syndrome, fever, hepatosplenomegaly, and thrombocytopenia. ${ }^{150}$ Intravascular large B cell lymphoma patients are often elderly and have poor prognostic factors as defined by the IPI, though this is less true of those with the cutaneous variant, which is seen mostly in Western populations. Treatment is with anthracycline-containing regimens such as R-CHOP, as for other forms of DLBCL but outcomes are poor. Use of high-dose methotrexate-based or high-dose cytarabinebased regimens has been advocated for patients with CNS involvement, given that these agents achieve higher levels within the CNS. ${ }^{150,151}$

\section{Follicular lymphoma}

FL is the most common indolent B cell NHL and consequently the prototype for indolent B cell lymphomas as a group. It results from malignant transformation of cells derived from the germinal follicle of lymphoid tissues, namely centrocytes and centroblasts. Grading of FL depends on the number and morphologic distribution of centroblasts within neoplastic follicles. The clinically relevant distinction is between low-grade (Grade 1-3A) FL, which will be discussed further below, and Grade 3B FL, which consists of sheets of centroblasts and is usually treated according to the DLBCL paradigm. ${ }^{152}$

\section{Clinical presentation}

FL most often comes to attention due to the development of peripheral lymphadenopathy. Central adenopathy may be found incidentally with medical imaging, or due to symptoms, though most patients do not have symptoms related to central adenopathy at presentation. It is an ageassociated disease which becomes more common in the sixth decade of life and beyond. Incidence rates differ with geography, being higher in Western countries than in Asia or Africa. Immigrants from Asia to western countries have an incidence rate that is intermediate between their native and adopted homes. ${ }^{48}$ B symptoms are uncommon, except in patients with transformed disease.

\section{Staging}

Routine lymphoma staging maneuvers are used in FL, with additional investigations targeted at sites of extranodal involvement such as the gastrointestinal tract. FDG-PET scanning after completion of therapy was recently evaluated in a subset of patients from the PRIMA trial, and found to predict progression-free survival independent of other known risk factors. ${ }^{153}$ Its inclusion in baseline staging allows subsequent comparison, but is not universally necessary. Among patients thought to have limited stage disease, which can be cured with radiotherapy, PET can be used to evaluate for additional occult sites of involvement. When transformed disease is a consideration, PET can be useful in determining which site of disease to biopsy.

With polymerase chain reaction (PCR)-based molecular techniques, bone marrow involvement can be demonstrated in $80 \%$ of patients, but medullary involvement carries little prognostic significance. ${ }^{154}$ The marrow space should be evaluated prior to start of treatment, and if involved should be re-examined at the time of restaging to determine response. Bone marrow evaluation is not universally necessary in asymptomatic patients with normal counts who do not meet criteria for immediate initiation of antilymphoma therapy. 


\section{Management}

Being both the most common and best studied indolent NHL, FL provides the paradigm by which the indolent lymphomas as a group are approached. Advanced disease, present in the majority of patients is considered to be incurable with standard therapies. Nonetheless, effective therapy is available, and with its use the disease follows a relapsingremitting course that now extends greater than 10 years from diagnosis in most patients.

Localized FL (ie, stage I or II within a single radiation port) can potentially be cured with IFRT. The proportion of patients who remain free of disease for more than 10 years after such treatment ranges from $20 \%-60 \%$ in various investigations. ${ }^{155-157}$ Relapses typically occur outside the radiation field, but more extensive nodal radiation has not been found to improve survival. Combined-modality therapy has also failed to show a clear survival benefit when compared with IFRT alone in early stage FL, although rituximab-containing regimens have not been evaluated. ${ }^{156}$

In advanced-stage disease, treatment is often administered only when specific criteria are met (Table 7), with the goal of decreasing disease burden and alleviating symptoms. ${ }^{158}$ Many patients can achieve long-term disease control with a series of intermittent treatments administered over a period of years. The natural history of FL is heterogeneous, with some patients' disease spontaneously remitting or remaining asymptomatic and untreated for years, while others experience rapid progression or histologic transformation to aggressive disease. The median time to treatment in initially observed patients is 3 years. ${ }^{159}$ The value of early initiation of therapy for nonbulky, asymptomatic FL has been revisited in the rituximab era; emerging data suggest that single-agent rituximab delays the need for subsequent therapy, but does not appear to prolong overall survival. ${ }^{160}$

Rituximab is now the mainstay of initial treatment and may be used as monotherapy or combined with alkylating agents,

Table 7 Criteria for initiation of therapy for advanced stage indolent lymphoma

Involvement of $\geq 3$ nodal sites, each with a diameter (long axis) of $\geq 3 \mathrm{~cm}$ Any nodal or extranodal tumor mass with a diameter (long axis) of $\geq 7 \mathrm{~cm}$ B symptoms

Symptomatic splenomegaly

Pleural effusions or abdominal ascites

Cytopenias (leukocytes $<\mathrm{I} \times 10^{9} / \mathrm{L}$ and/or platelets $<100 \times 10^{9} / \mathrm{L}$ )

Leukemic phase $\left(>5 \times 10^{9} / \mathrm{L}\right.$ malignant cells in peripheral blood)

Patient insistence

(c) Adapted from Solal-Celigny et al. Recombinant interferon alfa-2b combined with a regimen containing doxorubicin in patients with advanced follicular lymphoma Groupe d'Etude des Lymphomes de l'Adulte. N Eng J Med. 1993;329:1608-1614. purine analogs, or anthracycline-based cytotoxic regimens. The R-CHOP regimen has been the most widely used in the US, but a recently reported comparison with rituximab and bendamustine (R-Benda) demonstrated increased progression-free survival and less toxicity in the R-Benda group. ${ }^{161}$ Avoidance of anthracycline-containing therapy in the initial management of FL is preferred by some groups because it allows subsequent use of R-CHOP in those patients who experience histologic transformation to DLBCL. Increasing use of R-Benda will likely make such an approach more common.

When used to consolidate responses to salvage therapy in relapsed disease, HDT/ASCR is associated with longer remission duration than standard dose chemotherapy alone, and some groups have argued that such therapy may be curative in a proportion of patients. ${ }^{162,163}$ However, an increased rate of secondary malignancies is seen after HDT/ASCR, and despite the improvement in remission duration, an overall survival advantage has not been demonstrated in long-term follow-up. ${ }^{164,165}$ Allogeneic stem cell transplantation can be curative, but it is associated with significant morbidity and mortality and is therefore typically reserved for otherwise fit patients in whom the disease has followed an aggressive clinical course, including rapid recurrence or poor response to therapy. ${ }^{166,167}$ Given the advanced median age at which FL is diagnosed, many patients are ineligible for such an approach, and many of those who are eligible can be adequately managed with less intensive therapy.

Administration of rituximab in a maintenance fashion, with one dose every 2 months for up to 2 years following initial treatment with R-CHOP or R-CVP (cyclophosphamide, vincristine, prednisone), has recently been shown to improve progression-free survival. Although an overall survival benefit has not been clearly demonstrated in individual trials, a survival benefit has been found on meta-analysis. ${ }^{168,169}$

Radioimmunotherapy with the radiolabeled anti-CD20 antibodies, 90-Y-ibritumomab tiuxetan or 131-I-tositumomab, has been shown to produce high response rates in both the front-line and relapsed settings. ${ }^{170,171}$ When used to consolidate a response to an alternative first-line regimen, a single dose of 90-Y-ibritumomab tiuxetan has demonstrated significant improvement in progression-free survival, particularly benefiting patients with a partial response after first-line therapy, most of whom converted to a complete response with radioimmunotherapy. ${ }^{172}$

\section{Marginal zone lymphoma}

The marginal zone lymphomas (MZLs) are a group of diseases with morphologic similarity to cells found in the 
perifollicular margins of lymphoid tissues, including the spleen, where they were first characterized. ${ }^{173}$ However, despite their morphologic similarities, the three entities included in this group, ie, splenic MZL, extranodal MZL of MALT and bronchial-associated lymphoid tissue, and nodal MZL, are clinically and genetically distinct entities. The MZLs collectively account for about $12 \%$ of all NHL with MALT lymphoma, the most common MZL, comprising approximately $9 \%$. $^{7,8}$

\section{Splenic marginal zone lymphoma}

Splenic MZL typically presents in older patients (median age, 65 years) with symptoms related to splenomegaly, such as early satiety and abdominal fullness, or cytopenias resulting from hypersplenism, autoantibodies, or bone marrow infiltration. Involvement of bone marrow and peripheral blood are common, and circulating lymphoma cells can often be recognized by their villous cytoplasmic projections. Within the bone marrow, a characteristic pattern of intrasinusoidal infiltration is considered a hallmark of the disease. ${ }^{174}$ Lymphadenopathy is typically absent or low in volume. ${ }^{175} \mathrm{~A}$ minority of patients are infected with hepatitis $\mathrm{C}$ virus, and treatment of the infection seems to improve tumor burden in infected patients, though the interaction may be mediated by associated cryoglobulinemia. ${ }^{14,176-179}$ Splenic MZL is an indolent disease, with a median survival of approximately 13 years. ${ }^{180}$ Surgical splenectomy has traditionally been recommended for treatment of patients with cytopenias and symptomatic splenomegaly since it typically reverses both of these; interestingly, marrow infiltration is often seen to improve following debulking splenectomy. ${ }^{175}$ More recently, use of single agent rituximab has also shown high response rates, and avoids the operative and infectious risks associated with splenectomy. ${ }^{181}$ No direct comparison of rituximab with splenectomy has been undertaken, and the use of rituximab, either alone or in combination with cytotoxic chemotherapy, is currently recommended for patients who require treatment but are poor candidates for surgery.

\section{Extranodal marginal zone lymphoma of MALT}

MALT lymphoma is an indolent disease which may occur at various anatomic sites and is frequently preceded by an autoimmune or chronic infectious process, the best characterized of which is $H$. pylori-induced chronic gastritis in gastric MALT lymphoma. Other less well established and somewhat controversial associations include Chlamydia psittaci and ocular-adnexal MALT lymphoma, and hepatitis $\mathrm{C}$ virus and MALT lymphoma of various sites. The pathophysiology is thought to involve chronic stimulation of B lymphocytes by a persistent infection or autoimmune phenomenon resulting in clonal proliferation. Mutations occurring within the proliferating clone may subsequently confer antigen independence.

The clinical presentation of MALT lymphoma is usually related to local symptoms from the affected site. Anatomic sites at which MALT lymphoma may occur, other than the stomach, include the breast, thyroid, bowel, skin, soft tissue, and dura. The staging evaluation depends on the site of involvement, with endoscopy playing a key role in gastrointestinal disease and pulmonary function testing in bronchial-associated lymphoid tissue lymphoma. Otherwise, routine clinical staging (including $\mathrm{CT}$ and, if relevant, $\mathrm{PET}$ and bone marrow biopsy) is followed.

In the case of gastric MALT lymphoma, eradication of $H$. pylori is generally the first therapeutic maneuver, resulting in regression or remission in $50 \%-80 \%$ of earlystage patients. ${ }^{182}$ The $\mathrm{t}(11 ; 18)(\mathrm{q} 21 ; \mathrm{q} 21)$ chromosomal translocation results in antigen-independent activation of the $\mathrm{NF}-\kappa \mathrm{B}$ pathway, and is strongly predictive of the failure of H. pylori eradication alone. ${ }^{183}$ Definitive radiation therapy is recommended in such cases, and results in a 70\%-90\% cure rate. ${ }^{184,185}$ Chemotherapy can also be used in the setting of refractory localized disease, or in advanced-stage disease. ${ }^{186}$ No optimal regimen has been established, and alkylatorbased or purine analog-based therapies are frequently employed. Single-agent rituximab has a relatively low complete response rate, but is an appropriate consideration in the frail patient. The effectiveness of antimicrobial therapy for MALT lymphoma at sites other than the stomach has not been definitively established.

\section{Nodal marginal zone lymphoma}

Nodal MZL is an uncommon indolent neoplasm of small lymphocytes predominantly involving the lymph nodes. Morphologically, it resembles the nodal involvement of MALT lymphoma, but is a distinct disorder identified in practice primarily by the absence of extranodal disease. Evaluation of regional extranodal sites including the gastrointestinal tract for abdominal adenopathy, lungs for hilar or mediastinal adenopathy, and the thyroid and ocular adnexa for neck adenopathy, should be undertaken when nodal MZL is suspected to rule out unidentified MALT lymphoma. It is distinguished from other indolent lymphomas that commonly affect lymph nodes by its immunophenotype, which is characterized by lack of expression of certain 
antigens commonly seen in the other lymphomas, including CD10 (which is usually present in FL), CD5 (which is present in CLL/SLL and MCL), and CD23 (which is also present in most cases of CLL/SLL). Few data are available to guide treatment of nodal MZL specifically, and it is generally managed according to the FL paradigm with alkylatorbased or purine analog-based therapy in combination with rituximab when treatment is required (Table 7).

\section{Small lymphocytic lymphoma of chronic lymphocytic leukemia type}

CLL and CLL/SLL both refer to a single disease entity that can present with bone marrow and peripheral blood involvement, lymph node involvement or both. Cases presenting primarily with lymphadenopathy in the absence of peripheral blood involvement are called CLL/SLL, whereas cases having a peripheral lymphocytosis with an appropriate monoclonal phenotype, regardless of whether lymphadenopathy is also present, are called CLL. It is an indolent disease of the elderly, affecting about 14,500 patients per year in the US, with a median age at diagnosis of 72 years. ${ }^{6}$ It is more common among men than women and among non-Hispanic whites than either Hispanics or African Americans. ${ }^{187}$ Only about $10 \%$ of patients will have a primarily nodal presentation, making CLL/SLL a relatively uncommon lymphoma.

\section{Clinical presentation}

CLL/SLL, like other indolent lymphomas, typically comes to attention due to painless peripheral lymphadenopathy. In patients with peripheral blood involvement (ie, CLL), the diagnosis is often suspected due to an incidental finding of lymphocytosis on a peripheral blood cell count and subsequently confirmed by immunophenotyping with flow cytometry. Cytopenias in CLL can occur because of marrow involvement or peripheral destruction due to autoimmune phenomena, and may result in symptoms. Systemic B symptoms are present in $<20 \%$ of patients without transformed disease.

\section{Staging}

CLL-specific clinical staging systems include those of Rai and Binet. ${ }^{188,189}$ The Rai system has remained more popular in the US, and includes stage 0 disease consisting of blood and bone marrow involvement alone, with monoclonal lymphocytosis of $>5000$ cells $/ \mathrm{mm}^{3}$. This entity does not by definition include SLL/CLL, since no lymphadenopathy is present. Patients with monoclonal B cells in peripheral blood at a level $<5000$ cells $/ \mathrm{mm}^{3}$ and no other symptoms carry a diagnosis of monoclonal B cell lymphocytosis, and go on to develop overt CLL at a rate of $1.1 \%$ per year. ${ }^{190,191}$ Rai stages I, II, III, and IV are characterized by lymphadenopathy, hepatosplenomegaly, anemia, and thrombocytopenia, respectively, and these stages have prognostic significance. Both cross-sectional imaging with CT and functional imaging with FDG-PET are less well established in CLL than other lymphoid malignancies, and while imaging before and after systemic treatment are recommended in guidelines, the use of routine surveillance scans has been questioned. ${ }^{192}$ The utility of routine scans in the subset of patients with a predominately nodal presentation (ie, SLL/CLL) has not been specifically studied, but these patients are more likely to benefit from imaging since disease monitoring with peripheral blood counts is less feasible. Bone marrow biopsy is not required for diagnosis of CLL when peripheral blood is involved, but should be performed in cases that lack a leukemic phase. It is also helpful in patients with cytopenias at diagnosis, because it may allow distinction between marrow infiltration and autoimmune phenomena as the etiology. ${ }^{193}$

Analogous to Ann Arbor staging in other lymphomas, the Rai and Binet staging systems in CLL are limited in their prognostic utility. More recently, genetic profiling studies have revealed specific recurrent abnormalities with prognostic significance independent of stage. The most frequently occurring karyotypic abnormalities with demonstrated prognostic significance are deletion of $13 \mathrm{q}$, deletion of $11 \mathrm{q}$, which is the locus of the ATM gene and deletion of $17 \mathrm{p}$, which is the locus of the $p 53$ gene. ${ }^{194}$ While $13 \mathrm{q}$ deletions are associated with a more indolent course and favorable prognosis as compared with patients with normal cytogenetics, the latter two abnormalities are unfavorable.

Studies investigating the cell of origin in individual cases of CLL/SLL have also yielded new prognostic information. CLL/SLL can arise from naïve pregerminal center B lymphocytes or from post-germinal center memory B cells which are characterized by somatic mutation of immunoglobulin genes which have occurred in response to antigen stimulation in the germinal center. Patients without mutations of the variable region of the immunoglobulin heavy chain gene $\left(\operatorname{Ig~}_{\mathrm{H}}\right)$, which are therefore thought to arise from naïve $\mathrm{B}$ lymphocytes, have a poorer prognosis than those with mutated $\mathrm{Ig}_{\mathrm{H}}$ genes. An evaluation of early-stage patients, for example, reported median survival of 117 months for those with unmutated $\mathrm{Ig} \mathrm{V}_{\mathrm{H}}$ genes, compared with 293 months in those with mutated $\mathrm{Ig} \mathrm{V}_{\mathrm{H}}$ genes. ${ }^{195}$ 


\section{Management}

Like other indolent B cell neoplasms, CLL is incurable with conventional therapy, and the therapeutic goals are therefore to prolong the natural history of the disease and relieve symptoms when such occur. Patients who are asymptomatic and do not have cytopenias at the time of diagnosis can be safely observed without therapy, as demonstrated by an analysis of two trials using early chlorambucil in observable CLL patients which found improvement in survival with such an approach. ${ }^{196}$ As noted above, the estimated length of time that will elapse before treatment is indicated varies widely with the genetic and phenotypic features present in an individual case, as well as the stage.

Multiple regimens are available for treatment once it is indicated, and no initial treatment strategy has demonstrated clear superiority as measured by overall survival. The choice of therapy is individualized, with prognostic variables, patient characteristics, efficacy, and toxicity of the regimen all being considered. In practice, front-line therapy is commonly based on the purine analog, fludarabine, used in combination with rituximab with or without cyclophosphamide. ${ }^{197,198}$ Patients with p53 deletions or mutations have the worst overall prognosis of any group of CLL patients, and exhibit a poor response to fludarabine-based therapies. ${ }^{199}$ The antiCD52 monoclonal antibody, alemtuzumab, has shown similar activity in patients with p53 abnormalities as in patients without them, and is therefore an important consideration in this group..$^{200}$ Alemtuzumab is associated with prolonged immunodeficiency, and is less effective in treating nodal disease than medullary disease, making it less useful in the setting of bulky lymphadenopathy. ${ }^{201}$ The alkylating agent, bendamustine, often combined with rituximab, has excellent activity in the front line setting and in patients with relapsed disease ${ }^{202,203}$ Ofatumumab, a fully humanized anti-CD20 monoclonal antibody that binds a different CD20 epitope than rituximab, is active in fludarabine-refractory and alemtuzumab-refractory patients, regardless of prior rituximab exposure. ${ }^{204,205}$ Its use in less refractory patients and in combination with other agents (as well as in other lymphoma subtypes, most notably relapsed DLBCL) is a subject of ongoing investigation. Allogeneic hematopoietic stem cell transplant is the only curative option, and is usually considered in younger patients with high-risk disease or an aggressive course.

Histologic transformation of an indolent $\mathrm{B}$ cell neoplasm to DLBCL was first described in CLL where it is referred to as the Richter syndrome. ${ }^{206}$ It carries a worse prognosis than DLBCL arising outside the setting of an underlying CLL, but is managed similarly. New onset of systemic symptoms or a sudden increase in the pace of disease progression should prompt consideration of transformed disease. FDGPET scanning can be helpful in such cases, because lymph nodes containing transformed disease tend to have higher standard uptake value measurements than nontransformed nodes. ${ }^{31}$ As with transformation in the setting of other indolent lymphomas, pathologic confirmation is required to make a diagnosis of Richter syndrome; biopsy site can be guided by FDG-PET results.

\section{Mantle cell lymphoma}

Due to its morphologic similarity to other mature B cell lymphoid neoplasms, including CLL/SLL, MCL was only recognized as a distinct entity in the early 1990s when its characteristic genetic lesion, the $\mathrm{t}(11 ; 14)(\mathrm{q} 13 ; \mathrm{q} 32)$ translocation, was found to select for a group of patients with a shared and distinct natural history. This translocation places the CCND1 gene under the control of the immunoglobulin heavy chain promoter-enhancer, resulting in overexpression of cyclin D1, which is thought to be the key event in MCL pathogenesis, though it is insufficient in and of itself to produce the MCL phenotype. Rarely, MCL may lack overexpression of cyclin D1 but is shown to overexpress either cyclin D2 or cyclin D3. Cyclins other than cyclin D1 are not routinely evaluated, however, and identification of $t(11 ; 14)$ negative MCL can be difficult. Immunohistochemical testing for cyclins D2 and D3 may be considered for indeterminate cases of CD5+ small cell lymphomas that lack both CD23 and cyclin D1 expression, making the disease non-classical for CLL/SLL, MCL, or MZL. Canonically held to share the incurability of the indolent B-cell NHLs despite a clinical behavior that is often more aggressive, recent data investigating the use of aggressive first-line therapeutic approaches, including consolidation with HDT/ASCR, have suggested that a subset of patients may indeed be cured with such an approach.

\section{Clinical presentation}

MCL most often affects older men, with 2:1 male gender predominance and a median age at diagnosis of 65 years. Most patients present with stage IV disease, with frequent involvement of bone marrow, liver, and Waldeyer's ring. ${ }^{207}$ Gastrointestinal tract involvement is also very common, and can present along a spectrum from diffuse and symptomatic lymphomatous polyposis to an endoscopically normal lumen with microscopic disease in the absence of symptoms. Up to $80 \%$ of patients will have gastrointestinal 
tract involvement when endoscopy and blind biopsy are uniformly performed. Peripheral blood involvement is also common, making the distinction between MCL and CLL a frequently encountered clinical issue. Immunophenotypic and cytogenetic analysis (see Table 2) are required for accurate diagnosis. Morphologically defined blastoid and pleomorphic variants are associated with poorer prognosis. The blastoid variant may be present at the time of diagnosis or occur as a transformation from the common variant. ${ }^{208}$

\section{Staging}

In addition to the standard clinical staging evaluation, upper and lower endoscopy with blind luminal biopsies is likely to identify additional sites of disease involvement. Endoscopy is only likely to change management in patients who are otherwise considered to be early-stage and authorities differ on the need for such evaluation in asymptomatic, advancedstage patients. FDG-PET is useful in assessing for extranodal disease, is of prognostic value at the conclusion of induction therapy, and may in the future be useful in guiding responseadapted therapy. ${ }^{209}$ Bone marrow is frequently involved, and should be evaluated prior to initiation of therapy. The prognostic index used most often in MCL is the MIPI, which uses a mathematical algorithm to determine risk strata. ${ }^{40}$ A combined MIPI score can be calculated for those patients in whom proliferative rate has been measured by Ki-67 staining, and may improve prediction, because proliferative rate is the single most powerful prognostic variable in MCL. ${ }^{210}$

\section{Management}

Some uncertainty remains regarding the indications for initiation of treatment for MCL. Investigators have shown that deferral of first-line therapy in the absence of signs or symptoms that would necessitate treatment does not appear to affect outcomes adversely, although unlike FL, the median duration of observation prior to need for therapy is only 9 months. ${ }^{211}$ A subset of patients can remain asymptomatic without treatment for years, but it can be difficult to determine prospectively which patients fall into this category. ${ }^{212,213}$ In light of emerging data regarding outcomes following aggressive first-line therapy, many experts prefer to treat patients with newly diagnosed MCL regardless of disease or symptom burden.

Combined modality therapy with $4-6$ cycles of systemic therapy followed by involved field radiotherapy can be curative in the small proportion of patients who present with truly localized nodal disease. As noted above, bone marrow and gastrointestinal tract are frequently involved, even in asymptomatic patients, and should be carefully evaluated before embarking on such a treatment approach. In the majority of patients with advanced-stage disease, MCL is usually treated with combination chemoimmunotherapy, but the optimal regimen and timing of treatment have not been defined. R-CHOP chemotherapy has been the most commonly used regimen, and results in improved response rate and time to treatment failure than $\mathrm{CHOP}$ alone, but the complete response rate is $<50 \%$ and remissions are of less than 2 years in median duration. ${ }^{214}$ Rituximab and bendamustine may offer a somewhat longer response duration with less toxicity. ${ }^{161}$

Attempts to improve on these results have mostly involved intensification of initial therapy, with the goal of achieving complete response, often followed by consolidation with HDT/ASCR. The Nordic 2 regimen, for example, alternates rituximab, cyclophosphamide, doxorubicin, vincristine, and prednisone in maximally tolerated doses, with rituximab and high-dose cytarabine, with responders going on to receive high-dose therapy with BEAM or BEAC and autologous stem cell rescue. ${ }^{215}$ Unlike previously reported less intensive regimens, in which relapses continued to occur at a steady rate throughout long-term follow-up, the Nordic Lymphoma Group reported a plateau in progression-free survival curves at about 5 years, suggesting that durable remission can be achieved in a subset of patients, particularly the low-MIPI cohort. Others have also sought ways to pursue aggressive first-line therapy with both anthracycline and cytarabine, and programs such as alternating R-CHOP and R-DHAP have also shown great promise. Efforts must now focus on clarifying the optimal induction therapy, the role of PET in response-adapted therapy, the utility of inclusion of radioimmunotherapy as a component of consolidation, and the value of maintenance therapy.

Patients who are not candidates for intensive initial therapy, or who relapse after completing it, are routinely treated sequentially with various chemoimmunotherapy combinations and experience a variably relapsing and remitting course. A recent comparison of rituximab and bendamustine with R-CHOP in initial treatment of indolent lymphomas, which included patients with MCL, showed the former to have superior outcomes and less toxicity. ${ }^{161}$ Bendamustine has also shown promising activity in the relapse setting, as have several novel agents including bortezomib, lenalidomide, and temsirolimus. ${ }^{216-218}$ Allogeneic stem cell transplantation in consolidation of remission for patients with relapsed MCL is often a relevant consideration, and is performed with curative intent. 


\section{Burkitt's lymphoma}

Burkitt's lymphoma is among the most aggressive of all malignancies, with proliferation rates of $99 \%-100 \%$ and a natural history characterized by rapid progression to death in the absence of treatment. It is an uncommon lymphoma, occurring in three forms. The first described was the endemic form which affects children in specific geographic areas of endemic falciparum malaria, most often in Africa and classically presents with a mass in the jaw. The sporadic form typically occurs in industrialized countries, and involves abdominal organs and lymph nodes, and the immunodeficiency associated form is most often seen in HIV-positive patients. ${ }^{219}$ Use of antiretroviral therapy and attainment of adequate $\mathrm{CD} 4+$ counts do not appear to prevent the disease in HIV-positive patients. ${ }^{220}$ All forms of Burkitt's lymphoma are characterized molecularly by overexpression of the $c-m y c$ oncogene due to translocation of $c-m y c$ to an immunoglobulin gene locus.

\section{Staging}

The most commonly applied staging evaluation discriminates Burkitt's lymphoma into either low-risk or average-risk based upon clinical parameters. Low-risk patients have both a single site of disease (after complete staging) and a normal serum lactate dehydrogenase; although this defines a relatively small subset of patients, those with low-risk disease may be treated with less intensive therapy than patients with average risk. Burkitt's lymphoma has a propensity for involvement of both the CNS and the bone marrow, and these sites should be evaluated at presentation and use of CNS prophylaxis is routine in the absence of demonstrated involvement.

\section{Management}

Intensive combination chemotherapy regimens such as CODOX-M/IVAC or hyper-CVAD are typically used in the initial management of Burkitt's lymphoma, and should be instituted as early as possible given the tendency of the disease to progress rapidly. ${ }^{221,222}$ Rates of 5-year disease-free survival are in the $50 \%-75 \%$ range following such therapy. ${ }^{223}$ As noted above, CNS involvement is common, and both intrathecal therapy and incorporation of CNS-penetrating agents into the therapeutic regimen is routine. Tumor lysis syndrome is a common complication of therapy, and may be present even before treatment begins.

Burkitt's lymphoma is uniformly CD20+, providing a rationale for the inclusion of rituximab in treatment. Among elderly patients, the addition of rituximab to hyper-CVAD has demonstrated improved survival without excessive toxicity, but an increased risk of infectious complications has been seen in HIV-associated Burkitt's lymphoma. ${ }^{224,225}$ Recent data supporting the activity of R-dose adjusted EPOCH in Burkitt's lymphoma have led this to become a frequently recommended therapeutic approach, particularly in patients who would not tolerate CODOX-M/IVAC or with Burkitt-like lymphoma.

\section{Peripheral T cell lymphoma}

$\mathrm{T}$ cell diseases collectively comprise about $5 \%-10 \%$ of newly diagnosed NHL. Pathologic diagnosis of T cell lymphoma can be difficult, with high rates of interobserver and intraobserver variation. Expert review is recommended for these diagnoses, but even in expert hands, only about half of them can reliably be classified into specific disease entities. Immunophenotypic evaluation is essential for accurate classification, and can also assist in distinguishing reactive processes from lymphomas, with the former having normal $\mathrm{T}$ cell immunophenotypes and the latter frequently exhibiting aberrant expression of non-T cell antigens or loss of expression of normal $\mathrm{T}$ cell antigens. ${ }^{226}$ Demonstration of $\mathrm{T}$ cell clonality with assessment of the $\mathrm{T}$ cell receptor can also assist in this distinction, although clonality of $\mathrm{T}$ cell receptor rearrangement is not itself diagnostic of malignancy, as many reactive processes (eg, drug reaction or arthropod bite) can engender inflammatory responses with $\mathrm{T}$ cell receptor clonality. The molecular pathogenesis of $\mathrm{T}$ cell lymphomas in general is not well understood, and treatment paradigms have only recently begun to diverge from routine B NHL management strategies. We will herein review the three most common lymphomas that routinely present with nodal or systemic disease, the so-called peripheral $\mathrm{T}$ cell lymphomas, ie, PTCL-NOS, angioimmunoblastic T cell lymphoma, and anaplastic large cell lymphoma.

\section{PTCL-NOS}

The most common subtype of PTCL, representing 25\%-30\% of cases, PTCL-NOS includes a heterogeneous group of systemic $T$ cell neoplasms that do not otherwise fit into any of the specific subtypes. That said, PTCL-NOS is not a diagnosis of exclusion, but rather a distinct clinicopathologic entity. It has a median age of 60 years, a slight male predominance, and tends to present with advanced-stage disease. Common extranodal sites include liver, spleen, skin, subcutaneous tissue, and lungs. It has a poor prognosis, with 5-year overall survival of $32 \%$ in the largest published series. ${ }^{227}$ No randomized clinical trials have specifically addressed first-line therapy of PTCL-NOS. CHOP chemotherapy 
(with radiotherapy consolidation for early-stage disease) is commonly employed based on trials that included subsets of patients with $\mathrm{T}$ cell lymphomas. Response rates for patients with $\mathrm{T}$ cell lymphomas are inferior to those seen in B cell NHL, and less durable. ${ }^{227}$ Given these observations, consolidation of first-line response with HDT/ASCR is often considered, although such an approach remains investigational. The role of allogeneic stem cell transplant as consolidation remains experimental for PTCL-NOS, and is often reserved for relapsed diseases. ${ }^{228}$

Several investigations of intensified regimens have included various forms of aggressive lymphoma, with B cell lymphomas comprising the bulk of enrolled patients and various PTCLs only a minority. The applicability of the overall findings to PTCL as a whole and especially to individual subtypes of PTCLs is difficult to assess due to the smaller numbers. In one such study of aggressive lymphomas, the ACVBP (doxorubicin, cyclophosphamide, vindesine, bleomycin, prednisone) regimen used by GELA was compared with CHOP and showed improved overall survival, albeit at the expense of increased toxicity. ${ }^{229}$ The German High Grade Non-Hodgkin Lymphoma Study Group has shown that dosedense therapy (CHOP-14) and the addition of etoposide for younger (but not older) patients both improve outcomes, again in a somewhat heterogeneous population, including a minority of T cell lymphomas. ${ }^{129}$ Many novel agents are in various stages of development, including monoclonal antibodies and antibody-drug conjugates, histone deacetylase inhibitors, immunomodulatory agents, and proteasome inhibitors, and patients should be treated as part of a clinical trial whenever possible. Pralatrexate, a novel antifolate, is approved by the Food and Drug Administration for the treatment of relapsed or refractory PTCL. Its approval is based on an overall response rate of $29 \%$ with a median duration of 10.1 months in a group of 111 heavily pretreated PTCL patients in the Phase II PROPEL study. ${ }^{230}$ Romidepsin, an HDAC inhibitor, has also demonstrated single-agent activity in relapsed or refractory PTCL, and is now the second medication approved by the Food and Drug Administration for this indication.

\section{Angioimmunoblastic $T$ cell lymphoma}

Patients with angioimmunoblastic T cell lymphoma typically present in the sixth or seventh decade of life with systemic symptoms that include fever, weight loss, and rash, and physical examination and body imaging will most often reveal generalized, nonbulky lymphadenopathy. About $80 \%$ of patients are at an advanced stage at presentation. Hepatosplenomegaly and bone marrow infiltration are common, as are laboratory abnormalities, including anemia, polyclonal hypergammaglobulinemia, and eosinophilia. The pathologic features are distinctive, with prominent blood vessels, open sinuses, and occasional Epstein-Barr viruspositive $\mathrm{B}$ cells in affected lymph nodes, in addition to the neoplastic cells. The follicular T helper cell, a T helper subset found in the germinal center, has now been implicated as the cell of origin, though details of the molecular pathogenesis, like that of other $\mathrm{T}$ cell neoplasms, remain obscure. ${ }^{231}$ Angioimmunoblastic T cell lymphoma is an aggressive disease with a poor prognosis; 5 -year overall and failure-free survival among all patients are both $30 \%-40 \%{ }^{232}$ Patients have most commonly been treated with anthracycline-based regimens such as $\mathrm{CHOP}$, as used for B cell lymphomas, but results with this approach are poor, and retrospective analysis suggests that anthracycline-containing regimens are not clearly more effective than other regimens as stand-alone therapy, which is in contrast with the case seen in aggressive B cell diseases. ${ }^{233,234}$ Some patients will respond well to less intensive therapy that is more immunosuppressive in nature, including single-agent corticosteroids or cyclosporine. However, patients who are appropriate candidates for aggressive approaches may benefit from intensified firstline therapy. Retrospective and uncontrolled prospective evaluations suggest that outcomes may be better in patients with chemosensitive disease, whose initial remission is consolidated with HDT/ASCR. ${ }^{235,236}$ Disease status at the time of HDT/ASCR is an important prognostic variable in angioimmunoblastic T cell lymphoma, as it is with other lymphoma subtypes. Patients with complete remission at the time of consolidation therapy have superior outcomes. ${ }^{237}$

\section{Anaplastic large cell lymphoma}

The diagnosis of anaplastic large cell lymphoma has been applied most frequently to diseases of $\mathrm{T}$ cell or null cell origin, characterized by expression of the CD30 antigen, which is also expressed on the Reed-Sternberg cells of classical Hodgkin's lymphoma. Anaplastic large cell lymphoma is typically further classified as to whether or not overexpression of anaplastic lymphoma kinase (ALK) is present; the characteristic $\mathrm{t}(2 ; 5)$ translocation results in fusion of a nuclear protein gene and ALK. ${ }^{238}$ Patients with ALK+ anaplastic large cell lymphoma tend to be young (most commonly in the third or third decade of life), male, and present with advanced disease, whereas ALK- anaplastic large cell lymphoma tends to present later in life without the same male predominance. ${ }^{239}$ Unlike most PTCLs, ALK+ anaplastic large cell lymphoma (particularly in younger 
patients with lower IPI scores) typically carries a favorable prognosis when treated with CHOP chemotherapy alone, with 5-year overall survival rates of $70 \%-80 \%{ }^{239,240}$ ALKanaplastic large cell lymphoma bears closer resemblance to PTCL-NOS prognostically, and initial therapy of these two diseases has yet to diverge. Consolidation of CR1 for ALKanaplastic large cell lymphoma with HDT/ASCR is often recommended, although consolidative therapy for ALK+ anaplastic large cell lymphoma is typically considered only for high-risk IPI disease, older patients with ALK+ anaplastic large cell lymphoma, or relapsed disease. The management of relapsed ALCL lacks a standard of care, although the general pattern of reinduction and consolidation, typically with allogeneic stem cell transplantation, when feasible, holds true here as well. Of note, brentuximab vedotin, the anti-CD30 antibody-drug conjugate (see above), has demonstrated Phase II activity, with an overall response rate of $86 \%$ and a complete response rate of $57 \%,{ }^{89}$ earning it the distinction of being the first agent ever approved by the Food and Drug Administration for the treatment of relapsed anaplastic large cell lymphoma. Ongoing investigations will hopefully clarify the optimal use of this agent in anaplastic large cell lymphoma, exploring its incorporation into first-line therapy, relapsed disease as a component of multi-agent chemotherapy programs, and maintenance therapy both post-induction and post-consolidation.

\section{Summary}

The malignant lymphomas comprise a diverse and heterogeneous group of B cell and T cell malignancies that vary in their biology, epidemiology, natural history, response to treatment, and prognosis. They are organized based on cell of origin and our current understanding of the biology of each individual type within the structure of the WHO classification system. Management of malignant lymphomas begins with an accurate and specific diagnosis, based largely on thorough analysis of an adequate tissue specimen. Staging in lymphoma differs from that used in most solid tumors, and is less informative with regard to prognosis. Models that incorporate both patient and tumor specific variables can provide more detailed prognostic information and are used to guide treatment in some, but not all types of lymphoma. Though effective therapies are available for many types of lymphoma, a significant proportion of patients will ultimately develop relapsed or refractory disease. Areas of ongoing investigation will hopefully provide clinicians with more effective and less toxic therapies as well as greater sophistication in selecting optimal therapy for individual patients.

\section{Disclosure}

Dr Matasar receives research support from GlaxoSmithKline and has served on advisory boards for GlaxoSmithKline, Genentech, and Genzyme. Dr Word has no relationships/ potential conflicts of interest to declare.

\section{References}

1. Sheehan WW, Rappaport H. Morphological criteria in the classification of the malignant lymphomas. Proc Natl Cancer Conf. 1970;6:59-71.

2. [No authors listed]. National Cancer Institute sponsored study of classifications of non-Hodgkin's lymphomas: summary and description of a working formulation for clinical usage. The Non-Hodgkin's Lymphoma Pathologic Classification Project. Cancer. 1982;49(10):2112-2135.

3. Harris NL, Jaffe ES, Stein H, et al. A revised European-American classification of lymphoid neoplasms: a proposal from the International Lymphoma Study Group. Blood. 1994;84(5):1361-1392.

4. O'Brien S, Vose JM, Kantarjian H. Management of Hematologic Malignancies. Cambridge, UK: Cambridge University Press; 2011.

5. World Health Organization/International Agency for Research on Cancer. WHO Classification of Tumours of Haematopoietic and Lymphoid Tissues. Lyon, France: IARC Press; 2008.

6. Siegel R, Ward E, Brawley O, Jemal A. Cancer statistics, 2011: the impact of eliminating socioeconomic and racial disparities on premature cancer deaths. CA Cancer J Clin. 2011;61(4):212-236.

7. Armitage JO, Weisenburger DD. New approach to classifying nonHodgkin's lymphomas: clinical features of the major histologic subtypes. Non-Hodgkin's Lymphoma Classification Project. J Clin Oncol. 1998;16(8):2780-2795.

8. [No authors listed]. A clinical evaluation of the International Lymphoma Study Group classification of non-Hodgkin's lymphoma. The Non-Hodgkin's Lymphoma Classification Project. Blood. 1997;89(11):3909-3918.

9. Hjalgrim H, Askling J, Rostgaard K, et al. Characteristics of Hodgkin's lymphoma after infectious mononucleosis. $N$ Engl $J$ Med. 2003;349(14):1324-1332.

10. Randhawa PS, Jaffe R, Demetris AJ, et al. Expression of Epstein-Barr virus-encoded small RNA (by the EBER-1 gene) in liver specimens from transplant recipients with post-transplantation lymphoproliferative disease. N Engl J Med. 1992;327(24):1710-1714.

11. Gunven P, Klein G, Henle G, Henle W, Clifford P. Epstein-Barr virus in Burkitt's lymphoma and nasopharyngeal carcinoma. Antibodies to EBV associated membrane and viral capsid antigens in Burkitt lymphoma patients. Nature. 1970;228(5276):1053-1056.

12. Chua I, Quinti I, Grimbacher B. Lymphoma in common variable immunodeficiency: interplay between immune dysregulation, infection and genetics. Curr Opin Hematol. 2008;15(4):368-374.

13. Wotherspoon AC, Ortiz-Hidalgo C, Falzon MR, Isaacson PG. Helicobacter pylori-associated gastritis and primary B-cell gastric lymphoma. Lancet. 1991;338(8776):1175-1176.

14. Arcaini L, Paulli M, Boveri E, et al. Splenic and nodal marginal zone lymphomas are indolent disorders at high hepatitis $\mathrm{C}$ virus seroprevalence with distinct presenting features but similar morphologic and phenotypic profiles. Cancer. 2004;100(1):107-115.

15. Smedby KE, Baecklund E, Askling J. Malignant lymphomas in autoimmunity and inflammation: a review of risks, risk factors, and lymphoma characteristics. Cancer Epidemiol Biomarkers Prev. 2006;15(11):2069-2077.

16. Hooper WC, Holman RC, Clarke MJ, Chorba TL. Trends in nonHodgkin lymphoma (NHL) and HIV-associated NHL deaths in the United States. Am J Hematol. 2001;66(3):159-166.

17. Tirelli U, Spina M, Gaidano G, Vaccher E, Franceschi S, Carbone A. Epidemiological, biological and clinical features of HIV-related lymphomas in the era of highly active antiretroviral therapy. AIDS. 2000;14(12):1675-1688. 
18. Cartwright R, McNally R, Staines A. The increasing incidence of non-Hodgkin's lymphoma (NHL): the possible role of sunlight. Leuk Lymphoma. 1994;14(5-6):387-394.

19. Chiu BC, Weisenburger DD, Zahm SH, et al. Agricultural pesticide use, familial cancer, and risk of non-Hodgkin lymphoma. Cancer Epidemiol Biomarkers Prev. 2004;13(4):525-531.

20. Zahm SH, Weisenburger DD, Babbitt PA, Saal RC, Vaught JB, Blair A. Use of hair coloring products and the risk of lymphoma, multiple myeloma, and chronic lymphocytic leukemia. Am J Public Health. 1992;82(7):990-997.

21. Shugart YY, Hemminki K, Vaittinen P, Kingman A, Dong C. A genetic study of Hodgkin's lymphoma: an estimate of heritability and anticipation based on the familial cancer database in Sweden. Hum Genet. 2000;106(5):553-556.

22. Wang SS, Slager SL, Brennan P, et al. Family history of hematopoietic malignancies and risk of non-Hodgkin lymphoma (NHL): a pooled analysis of 10,211 cases and 11,905 controls from the International Lymphoma Epidemiology Consortium (InterLymph). Blood. 2007;109(8):3479-3488.

23. Zhu K, Levine RS, Brann EA, et al. Risk factors for non-Hodgkin's lymphoma according to family history of haematolymphoproliferative malignancies. Int J Epidemiol. 2001;30(4):818-824.

24. AltieriA, Bermejo JL, Hemminki K. Familial risk for non-Hodgkin lymphoma and other lymphoproliferative malignancies by histopathologic subtype: the Swedish Family-Cancer Database. Blood. 2005;106(2):668-672.

25. Zelenetz AD, Hoppe RT. NCCN: Non-Hodgkin's lymphoma. Cancer Control. 2001;8(6 Suppl 2):102-113.

26. [No authors listed]. NCCN practice guidelines for Hodgkin's disease. National Comprehensive Cancer Network. Oncology (Williston Park) 1999;13(5A):78-110.

27. Mourad WA, Tulbah A, Shoukri M, et al. Primary diagnosis and REAL/WHO classification of non-Hodgkin's lymphoma by fine-needle aspiration: cytomorphologic and immunophenotypic approach. Diagn Cytopathol. 2003;28(4):191-195.

28. Young NA, Al-Saleem TI, Ehya H, Smith MR. Utilization of fineneedle aspiration cytology and flow cytometry in the diagnosis and subclassification of primary and recurrent lymphoma. Cancer. 1998;84(4):252-261.

29. Matasar MJ, Shi W, Silberstien J, et al. Expert second-opinion pathology review of lymphoma in the era of the World Health Organization classification. Ann Oncol. 2012;23(1):159-166.

30. LaCasce AS, Kho ME, Friedberg JW, et al. Comparison of referring and final pathology for patients with non-Hodgkin's lymphoma in the National Comprehensive Cancer Network. J Clin Oncol. 2008;26(31):5107-5112.

31. Noy A, Schoder H, Gonen M, et al. The majority of transformed lymphomas have high standardized uptake values (SUVs) on positron emission tomography (PET) scanning similar to diffuse large B-cell lymphoma (DLBCL). Ann Oncol. 2009;20(3):508-512.

32. Lister TA, Crowther D, Sutcliffe SB, et al. Report of a committee convened to discuss the evaluation and staging of patients with Hodgkin's disease: Cotswolds meeting. J Clin Oncol. 1989;7(11):1630-1636.

33. Hasenclever D, Diehl V. A prognostic score for advanced Hodgkin's disease. International Prognostic Factors Project on Advanced Hodgkin's Disease. N Engl J Med. 1998;339(21):1506-1514.

34. Gospodarowicz MK, Sutcliffe SB, Clark RM, et al. Analysis of supradiaphragmatic clinical stage I and II Hodgkin's disease treated with radiation alone. Int J Radiat Oncol Biol Phys. 1992;22(5):859-865.

35. Henry-Amar M, Friedman S, Hayat M, et al. Erythrocyte sedimentation rate predicts early relapse and survival in early-stage Hodgkin disease. The EORTC Lymphoma Cooperative Group. Ann Intern Med. 1991;114(5):361-365.

36. Duhmke E, Diehl V, Loeffler M, et al. Randomized trial with early-stage Hodgkin's disease testing 30 Gy vs 40 Gy extended field radiotherapy alone. Int J Radiat Oncol Biol Phys. 1996;36(2):305-310.

37. [No authors listed]. A predictive model for aggressive non-Hodgkin's lymphoma. The International Non-Hodgkin's Lymphoma Prognostic Factors Project. N Engl J Med. 1993;329(14):987-994.
38. Solal-Celigny P, Roy P, Colombat P, et al. Follicular lymphoma international prognostic index. Blood. 2004;104(5):1258-1265.

39. Federico M, Bellei M, Marcheselli L, et al. Follicular lymphoma international prognostic index 2: a new prognostic index for follicular lymphoma developed by the international follicular lymphoma prognostic factor project. J Clin Oncol. 2009;27(27):4555-4562.

40. Hoster E, Dreyling M, Klapper W, et al. A new prognostic index (MIPI) for patients with advanced-stage mantle cell lymphoma. Blood. 2008;111(2):558-565.

41. Gallamini A, Stelitano C, Calvi R, et al. Peripheral T-cell lymphoma unspecified (PTCL-U): a new prognostic model from a retrospective multicentric clinical study. Blood. 2004;103(7):2474-2479.

42. Went P, Agostinelli C, Gallamini A, et al. Marker expression in peripheral T-cell lymphoma: a proposed clinical-pathologic prognostic score. J Clin Oncol. 2006;24(16):2472-2479.

43. Hamlin PA, Zelenetz AD, Kewalramani T, et al. Age-adjusted International Prognostic Index predicts autologous stem cell transplantation outcome for patients with relapsed or primary refractory diffuse large B-cell lymphoma. Blood. 2003;102(6):1989-1996.

44. Miller TP, Dahlberg S, Cassady JR, et al. Chemotherapy alone compared with chemotherapy plus radiotherapy for localized intermediate- and high-grade non-Hodgkin's lymphoma. N Engl J Med. 1998;339(1):21-26.

45. Hasenclever D. The disappearance of prognostic factors in Hodgkin's disease. Ann Oncol. 2002;(13 Suppl 1):75-78.

46. Sehn LH, Berry B, Chhanabhai M, et al. The revised International Prognostic Index (R-IPI) is a better predictor of outcome than the standard IPI for patients with diffuse large B-cell lymphoma treated with R-CHOP. Blood. 2007;109(5):1857-1861.

47. Kuppers R, Rajewsky K, Zhao M, et al. Hodgkin disease: Hodgkin and Reed-Sternberg cells picked from histological sections show clonal immunoglobulin gene rearrangements and appear to be derived from B cells at various stages of development. Proc Natl Acad Sci US A. 1994;91(23):10962-10966.

48. Morton LM, Wang SS, Devesa SS, Hartge P, Weisenburger DD, Linet MS. Lymphoma incidence patterns by WHO subtype in the United States, 1992-2001. Blood. 2006;107(1):265-276.

49. Brousset P, Knecht H, Rubin B, et al. Demonstration of Epstein-Barr virus replication in Reed-Sternberg cells of Hodgkin's disease. Blood. 1993;82(3):872-876.

50. Mani H, Jaffe ES. Hodgkin lymphoma: an update on its biology with new insights into classification. Clin Lymphoma Myeloma. 2009;9(3):206-216.

51. Klimm B, Franklin J, Stein H, et al. Lymphocyte-depleted classical Hodgkin's lymphoma: a comprehensive analysis from the German Hodgkin Study Group. J Clin Oncol. 2011;29(29):3914-3920.

52. Mauch PM, Kalish LA, Kadin M, Coleman CN, Osteen R, Hellman S. Patterns of presentation of Hodgkin disease. Implications for etiology and pathogenesis. Cancer. 1993;71(6):2062-2071.

53. Vassilakopoulos TP, Angelopoulou MK, Siakantaris MP, et al. Pure infradiaphragmatic Hodgkin's lymphoma. Clinical features, prognostic factor and comparison with supradiaphragmatic disease. Haematologica. 2006;91(1):32-39.

54. Kalkner KM, Enblad G, Gustavsson A, et al. Infradiaphragmatic Hodgkin's disease: the Swedish National Care Programme experience. The Swedish Lymphoma Study Group. Eur J Haematol. 1997; 59(1):31-37.

55. Ifrah N, Hunault M, Jais JP, et al. Infradiaphragmatic Hodgkin's disease: long term results of combined modality therapy. Leuk Lymphoma. 1996;21(1-2):79-84.

56. Hammack J, Kotanides H, Rosenblum MK, Posner JB. Paraneoplastic cerebellar degeneration. II. Clinical and immunologic findings in 21 patients with Hodgkin's disease. Neurology. 1992;42(10): 1938-1943.

57. Gobbi PG, Attardo-Parrinello G, Lattanzio G, Rizzo SC, Ascari E. Severe pruritus should be a B-symptom in Hodgkin's disease. Cancer. 1983;51(10):1934-1936. 
58. Gobbi PG, Cavalli C, Gendarini A, et al. Reevaluation of prognostic significance of symptoms in Hodgkin's disease. Cancer. 1985;56(12):2874-2880.

59. Atkinson K, Austin DE, McElwain TJ, Peckham MJ. Alcohol pain in Hodgkin's disease. Cancer. 1976;37(2):895-899.

60. Gallamini A, Hutchings M, Rigacci L, et al. Early interim 2-[18F]fluoro2-deoxy-D-glucose positron emission tomography is prognostically superior to international prognostic score in advanced-stage Hodgkin's lymphoma: a report from a joint Italian-Danish study. J Clin Oncol. 2007;25(24):3746-3752.

61. Zinzani PL, Tani M, Fanti S, et al. Early positron emission tomography (PET) restaging: a predictive final response in Hodgkin's disease patients. Ann Oncol. 2006;17(8):1296-1300.

62. Hutchings M, Loft A, Hansen M, et al. FDG-PET after two cycles of chemotherapy predicts treatment failure and progression-free survival in Hodgkin lymphoma. Blood. 2006;107(1):52-59.

63. Barnes JA, LaCasce AS, Zukotynski K, et al. End-of-treatment but not interim PET scan predicts outcome in nonbulky limited-stage Hodgkin's lymphoma. Ann Oncol. 2011;22(4):910-915.

64. Press OW, LeBlanc M, Lichter AS, et al. Phase III randomized intergroup trial of subtotal lymphoid irradiation versus doxorubicin, vinblastine, and subtotal lymphoid irradiation for stage IA to IIA Hodgkin's disease. J Clin Oncol. 2001;19(22):4238-4244.

65. Noordijk EM, Carde P, Dupouy N, et al. Combined-modality therapy for clinical stage I or II Hodgkin's lymphoma: long-term results of the European Organisation for Research and Treatment of Cancer H7 randomized controlled trials. J Clin Oncol. 2006;24(19): 3128-3135.

66. Meyer RM, Gospodarowicz MK, Connors JM, et al. Randomized comparison of ABVD chemotherapy with a strategy that includes radiation therapy in patients with limited-stage Hodgkin's lymphoma: National Cancer Institute of Canada Clinical Trials Group and the Eastern Cooperative Oncology Group. J Clin Oncol. 2005;23(21): 4634-4642.

67. Straus DJ, Portlock CS, Qin J, et al. Results of a prospective randomized clinical trial of doxorubicin, bleomycin, vinblastine, and dacarbazine (ABVD) followed by radiation therapy (RT) versus ABVD alone for stages I, II, and IIIA nonbulky Hodgkin disease. Blood. 2004;104(12):3483-3489.

68. Aleman BM, van den Belt-Dusebout AW, Klokman WJ, Van't Veer MB, Bartelink H, van Leeuwen FE. Long-term cause-specific mortality of patients treated for Hodgkin's disease. J Clin Oncol. 2003;21(18):3431-3439.

69. Bonadonna G, Zucali R, Monfardini S, De Lena M, Uslenghi C. Combination chemotherapy of Hodgkin's disease with adriamycin, bleomycin, vinblastine, and imidazole carboxamide versus MOPP. Cancer. 1975;36(1):252-259.

70. Canellos GP, Anderson JR, Propert KJ, et al. Chemotherapy of advanced Hodgkin's disease with MOPP, ABVD, or MOPP alternating with ABVD. N Engl J Med. 1992;327(21):1478-1484.

71. Carde $\mathrm{P}$, Hagenbeek A, Hayat M, et al. Clinical staging versus laparotomy and combined modality with MOPP versus ABVD in early-stage Hodgkin's disease: the H6 twin randomized trials from the European Organization for Research and Treatment of Cancer Lymphoma Cooperative Group. J Clin Oncol. 1993;11(11):2258-2272.

72. Bonadonna G, Bonfante V, Viviani S, Di Russo A, Villani F, Valagussa P. ABVD plus subtotal nodal versus involved-field radiotherapy in early-stage Hodgkin's disease: long-term results. J Clin Oncol. 2004;22(14):2835-2841.

73. Engert A, Plutschow A, Eich HT, et al. Reduced treatment intensity in patients with early-stage Hodgkin's lymphoma. $N$ Engl J Med. 2010;363(7):640-652.

74. Canellos GP, Abramson JS, Fisher DC, LaCasce AS. Treatment of favorable, limited-stage Hodgkin's lymphoma with chemotherapy without consolidation by radiation therapy. J Clin Oncol. 2010;28(9): 1611-1615.
75. Horning SJ, Hoppe RT, Breslin S, Bartlett NL, Brown BW, Rosenberg SA. Stanford $\mathrm{V}$ and radiotherapy for locally extensive and advanced Hodgkin's disease: mature results of a prospective clinical trial. J Clin Oncol. 2002;20(3):630-637.

76. Gordon LI, Hong F, Fisher RI, et al. A randomized Phase III trial of ABVD vs Stanford V +/- radiation therapy in locally extensive and advanced stage Hodgkin's lymphoma: An Intergroup study coordinated by the Eastern Cooperative Oncology Group (E2496). Blood. 2010;116: Abstr 415

77. Advani RH, Hong F, Fisher RI, et al. Randomized Phase III trial comparing $\mathrm{ABVD}+$ radiotherapy and the Stanford $\mathrm{V}$ regimen in patients with stage I/II bulky mediastinal Hodgkin lymphoma: a subset analysis of the US Intergroup trial E2496. Blood. 2010;116.

78. Diehl V, Franklin J, Pfreundschuh M, et al. Standard and increaseddose BEACOPP chemotherapy compared with COPP-ABVD for advanced Hodgkin's disease. $N$ Engl J Med. 2003;348(24): 2386-2395.

79. Viviani S, Zinzani PL, Rambaldi A, et al. ABVD versus BEACOPP for Hodgkin's lymphoma when high-dose salvage is planned. $N \mathrm{Engl}$ J Med. 2011;365(3):203-212.

80. Jagannath S, Armitage JO, Dicke KA, et al. Prognostic factors for response and survival after high-dose cyclophosphamide, carmustine, and etoposide with autologous bone marrow transplantation for relapsed Hodgkin's disease. J Clin Oncol. 1989;7(2):179-185.

81. Linch DC, Winfield D, Goldstone AH, et al. Dose intensification with autologous bone-marrow transplantation in relapsed and resistant Hodgkin's disease: results of a BNLI randomised trial. Lancet. 1993;341(8852):1051-1054.

82. Reece DE, Connors JM, Spinelli JJ, et al. Intensive therapy with cyclophosphamide, carmustine, etoposide $+/-$ cisplatin, and autologous bone marrow transplantation for Hodgkin's disease in first relapse after combination chemotherapy. Blood. 1994;83(5):1193-1199.

83. Horning SJ, Chao NJ, Negrin RS, et al. High-dose therapy and autologous hematopoietic progenitor cell transplantation for recurrent or refractory Hodgkin's disease: analysis of the Stanford University results and prognostic indices. Blood. 1997;89(3):801-813.

84. Moskowitz CH, Nimer SD, Zelenetz AD, et al. A 2-step comprehensive high-dose chemoradiotherapy second-line program for relapsed and refractory Hodgkin disease: analysis by intent to treat and development of a prognostic model. Blood. 2001;97(3):616-623.

85. Schmitz N, Pfistner B, Sextro M, et al. Aggressive conventional chemotherapy compared with high-dose chemotherapy with autologous haemopoietic stem-cell transplantation for relapsed chemosensitive Hodgkin's disease: a randomised trial. Lancet. 2002;359(9323): 2065-2071.

86. Moskowitz CH, Kewalramani T, Nimer SD, Gonzalez M, Zelenetz AD, Yahalom J. Effectiveness of high dose chemoradiotherapy and autologous stem cell transplantation for patients with biopsy-proven primary refractory Hodgkin's disease. Br J Haematol. 2004;124(5): 645-652.

87. Peggs KS, Hunter A, Chopra R, et al. Clinical evidence of a graftversus-Hodgkin's-lymphoma effect after reduced-intensity allogeneic transplantation. Lancet. 2005;365(9475):1934-1941.

88. Anderlini P, Saliba R, Acholonu S, et al. Reduced-intensity allogeneic stem cell transplantation in relapsed and refractory Hodgkin's disease: low transplant-related mortality and impact of intensity of conditioning regimen. Bone Marrow Transplant. 2005;35(10):943-951.

89. Younes A, Bartlett NL, Leonard JP, et al. Brentuximab vedotin (SGN-35) for relapsed CD30-positive lymphomas. $N$ Engl J Med. 2010;363(19):1812-1821.

90. Regula DP Jr, Hoppe RT, Weiss LM. Nodular and diffuse types of lymphocyte predominance Hodgkin's disease. $N$ Engl J Med. 1988;318(4):214-219.

91. Ohno T, Stribley JA, Wu G, Hinrichs SH, Weisenburger DD, Chan WC. Clonality in nodular lymphocyte-predominant Hodgkin's disease. N Engl J Med. 1997;337(7):459-465. 
92. Marafioti T, Hummel M, Anagnostopoulos I, et al. Origin of nodular lymphocyte-predominant Hodgkin's disease from a clonal expansion of highly mutated germinal-center B cells. $N$ Engl $J$ Med. 1997;337(7):453-458.

93. Diehl V, Sextro M, Franklin J, et al. Clinical presentation, course, and prognostic factors in lymphocyte-predominant Hodgkin's disease and lymphocyte-rich classical Hodgkin's disease: report from the European Task Force on Lymphoma Project on Lymphocyte-Predominant Hodgkin's Disease. J Clin Oncol. 1999;17(3):776-783.

94. Hutchings M, Loft A, Hansen M, Ralfkiaer E, Specht L. Different histopathological subtypes of Hodgkin lymphoma show significantly different levels of FDG uptake. Hematol Oncol. 2006;24(3): 146-150.

95. Fanale MA, Lai C-M, McLaughlin P, et al. Outcomes of nodular lymphocyte predominant Hodgkin's lymphoma (NLPHL) patients treated with R-CHOP. ASH Annual Meeting Abstracts. 2010;116(21): 2812.

96. Schulz H, Rehwald U, Morschhauser F, et al. Rituximab in relapsed lymphocyte-predominant Hodgkin lymphoma: long-term results of a phase 2 trial by the German Hodgkin Lymphoma Study Group (GHSG). Blood. 2008;111(1):109-111.

97. Eichenauer DA, Fuchs M, Pluetschow A, et al. Phase II study of rituximab in newly diagnosed stage IA nodular lymphocyte-predominant Hodgkin lymphoma: a report from the German Hodgkin Study Group. Blood. 2011;118:4363-4365.

98. Orlandi E, Lazzarino M, Brusamolino E, et al. Nodular lymphocyte predominance Hodgkin's disease: long-term observation reveals a continuous pattern of recurrence. Leuk Lymphoma. 1997;26(3-4): 359-368.

99. Wright G, Tan B, Rosenwald A, Hurt EH, Wiestner A, Staudt LM. A gene expression-based method to diagnose clinically distinct subgroups of diffuse large B cell lymphoma. Proc Natl Acad Sci USA. 2003;100(17):9991-9996.

100. Rosenwald A, Wright G, Chan WC, et al. The use of molecular profiling to predict survival after chemotherapy for diffuse large-B-cell lymphoma. N Engl J Med. 2002;346(25):1937-1947.

101. Shipp MA, Ross KN, Tamayo P, et al. Diffuse large B-cell lymphoma outcome prediction by gene-expression profiling and supervised machine learning. Nat Med. 2002;8(1):68-74.

102. Lenz G, Wright G, Dave $\mathrm{S}$, et al. Gene expression signatures predict overall survival in diffuse large $\mathrm{B}$ cell lymphoma treated with rituximab and CHOP-like chemotherapy. ASH Annual Meeting Abstracts. 2007;110(11):348.

103. Hans CP, Weisenburger DD, Greiner TC, et al. Confirmation of the molecular classification of diffuse large B-cell lymphoma by immunohistochemistry using a tissue microarray. Blood. 2004;103(1):275-282.

104. Lossos IS, Czerwinski DK, Alizadeh AA, et al. Prediction of survival in diffuse large-B-cell lymphoma based on the expression of six genes. N Engl J Med. 2004;350(18):1828-1837.

105. Gutierrez-Garcia G, Cardesa-Salzmann T, Climent F, et al. Gene-expression profiling and not immunophenotypic algorithms predicts prognosis in patients with diffuse large B-cell lymphoma treated with immunochemotherapy. Blood. 2011;117(18):4836-4843.

106. Meyer PN, Fu K, Greiner TC, et al. Immunohistochemical methods for predicting cell of origin and survival in patients with diffuse large B-cell lymphoma treated with rituximab. J Clin Oncol. 2011;29(2): 200-207.

107. Moller MB, Pedersen NT, Christensen BE. Diffuse large B-cell lymphoma: clinical implications of extranodal versus nodal presentation - a population-based study of 1575 cases. Br J Haematology. 2004;124(2):151-159.

108. López-Guillermo A, Colomo L, Jiménez M, et al. Diffuse large B-cell lymphoma: clinical and biological characterization and outcome according to the nodal or extranodal primary origin. J Clin Oncol. 2005;23(12):2797-2804.
109. Montoto S, Davies AJ, Matthews J, et al. Risk and clinical implications of transformation of follicular lymphoma to diffuse large B-cell lymphoma. J Clin Oncol. 2007;25(17):2426-2433.

110. Yuen AR, Kamel OW, Halpern J, Horning SJ. Long-term survival after histologic transformation of low-grade follicular lymphoma. J Clin Oncol. 1995;13(7):1726-1733.

111. Bastion Y, Sebban C, Berger F, et al. Incidence, predictive factors, and outcome of lymphoma transformation in follicular lymphoma patients. J Clin Oncol. 1997;15(4):1587-1594.

112. Zelenetz AD, Chen TT, Levy R. Histologic transformation of follicular lymphoma to diffuse lymphoma represents tumor progression by a single malignant B cell. J Exp Med. 1991;173(1):197-207.

113. Matolcsy A, Inghirami G, Knowles D. Molecular genetic demonstration of the diverse evolution of Richter's syndrome chronic lymphocytic leukemia and subsequent large cell lymphoma. Blood. 1994;83(5):1363-1372.

114. Hollender A, Kvaloy S, Nome O, Skovlund E, Lote K, Holte H. Central nervous system involvement following diagnosis of non-Hodgkin's lymphoma: a risk model. Ann Oncol. 2002;13(7):1099-1107.

115. Haioun C, Besson C, Lepage E, et al. Incidence and risk factors of central nervous system relapse in histologically aggressive non-Hodgkin's lymphoma uniformly treated and receiving intrathecal central nervous system prophylaxis: a GELA study on 974 patients. Groupe d'Etudes des Lymphomes de 1'Adulte. Ann Oncol. 2000;11(6):685-690.

116. Ryan GF, Roos DR, Seymour JF. Primary non-Hodgkin's lymphoma of the breast: retrospective analysis of prognosis and patterns of failure in two Australian centers. Clin Lymphoma Myeloma. 2006;6(4):337-341.

117. Gholam D, Bibeau F, El Weshi A, Bosq J, Ribrag V. Primary breast lymphoma. Leuk Lymphoma. 2003;44(7):1173-1178.

118. Ganjoo K, Advani R, Mariappan MR, McMillan A, Horning S. Non-Hodgkin lymphoma of the breast. Cancer. 2007;110(1):25-30.

119. Korfel A. Prevention of central nervous system relapses in diffuse large B-cell lymphoma: which patients and how? Curr Opin Oncol. 2011;23(5):436-440.

120. McKelvey EM, Gottlieb JA, Wilson HE, et al. Hydroxyldaunomycin (Adriamycin) combination chemotherapy in malignant lymphoma. Cancer. 1976;38(4):1484-1493.

121. Fisher RI, Gaynor ER, Dahlberg S, et al. Comparison of a standard regimen (CHOP) with three intensive chemotherapy regimens for advanced non-Hodgkin's lymphoma. $N$ Engl $J$ Med. 1993;328(14):1002-1006.

122. Pfreundschuh M, Schubert J, Ziepert M, et al. Six versus eight cycles of bi-weekly CHOP-14 with or without rituximab in elderly patients with aggressive CD20+ B-cell lymphomas: a randomised controlled trial (RICOVER-60). Lancet Oncol. 2008;9(2):105-116.

123. Pfreundschuh M, Trumper L, Osterborg A, et al. CHOP-like chemotherapy plus rituximab versus $\mathrm{CHOP}-$ like chemotherapy alone in young patients with good-prognosis diffuse large-B-cell lymphoma: a randomised controlled trial by the MabThera International Trial (MInT) Group. Lancet Oncol. 2006;7(5):379-391.

124. Coiffier B, Lepage E, Briere J, et al. CHOP chemotherapy plus rituximab compared with $\mathrm{CHOP}$ alone in elderly patients with diffuse large-B-cell lymphoma. $N$ Engl J Med. 2002;346(4):235-242.

125. Habermann TM, Weller EA, Morrison VA, et al. Rituximab-CHOP versus $\mathrm{CHOP}$ alone or with maintenance rituximab in older patients with diffuse large B-cell lymphoma. J Clin Oncol. 2006;24(19): 3121-3127.

126. Feugier P, Van Hoof A, Sebban C, et al. Long-term results of the R-CHOP study in the treatment of elderly patients with diffuse large B-cell lymphoma: a study by the Groupe d'Etude des Lymphomes de l'Adulte. J Clin Oncol. 2005;23(18):4117-4126.

127. Miller TP, Unger JM, Spier C, et al. Effect of adding rituximab to three cycles of CHOP plus invoved-field radiotherapy for limited-stage aggressive diffuse B-cell lymphoma (SWOG-0014). ASH Annual Meeting Abstracts. 2004;104(11):158. 
128. Simon R, Norton L. The Norton-Simon hypothesis: designing more effective and less toxic chemotherapeutic regimens. Nat Clin Pract Oncol. 2006;3(8):406-407.

129. Pfreundschuh M, Trumper L, Kloess M, et al. Two-weekly or 3-weekly CHOP chemotherapy with or without etoposide for the treatment of elderly patients with aggressive lymphomas: results of the NHL-B2 trial of the DSHNHL. Blood. 2004;104(3):634-641.

130. Delarue R, Tilly H, Salles G, et al. R-CHOP14 compared to R-CHOP21 in elderly patients with diffuse large B-cell lymphoma: results of the interim analysis of the LNH03-6B GELA study. $A S H$ Annual Meeting Abstracts. 2009;114(22):406.

131. Cunningham D, Smith P, Mouncey P, et al. R-CHOP14 versus R-CHOP21: Result of a randomized Phase III trial for the treatment of patients with newly diagnosed diffuse large B-cell non-Hodgkin lymphoma. ASCO Meeting Abstracts. 2011;29(15 Suppl):8000.

132. Wilson WH. Drug resistance in diffuse large B-cell lymphoma. Semin Hematol. 2006;43(4):230-239.

133. Wilson WH, Dunleavy K, Pittaluga S, et al. Phase II study of doseadjusted EPOCH and rituximab in untreated diffuse large B-cell lymphoma with analysis of germinal center and post-germinal center biomarkers. J Clin Oncol. 2008;26(16):2717-2724.

134. Aukema SM, Siebert R, Schuuring E, et al. Double-hit B-cell lymphomas. Blood. 2011;117(8):2319-2331.

135. Moskowitz $\mathrm{CH}$, Schoder H, Teruya-Feldstein J, et al. Risk-adapted dose-dense immunochemotherapy determined by interim FDG-PET in advanced-stage diffuse large B-cell lymphoma. J Clin Oncol. 2010;28(11):1896-1903.

136. Gianni AM, Bregni M, Siena S, et al. High-dose chemotherapy and autologous bone marrow transplantation compared with MACOP-B in aggressive B-cell lymphoma. $N$ Engl J Med. 1997;336(18): 1290-1297.

137. Gisselbrecht C, Glass B, Mounier N, et al. Salvage regimens with autologous transplantation for relapsed large B-cell lymphoma in the rituximab era. J Clin Oncol. 2010;28(27):4184-4190.

138. van Kampen RJW, Canals C, Schouten HC, et al. Allogeneic stemcell transplantation as salvage therapy for patients with diffuse large B-cell non-Hodgkin's lymphoma relapsing after an autologous stem-cell transplantation: an analysis of the European Group for Blood and Marrow Transplantation Registry. J Clin Oncol. 2011;29(10):1342-1348.

139. Savage KJ, Monti S, Kutok JL, et al. The molecular signature of mediastinal large B-cell lymphoma differs from that of other diffuse large B-cell lymphomas and shares features with classical Hodgkin lymphoma. Blood. 2003;102(12):3871-3879.

140. Staudt LM, Dave S. The biology of human lymphoid malignancies revealed by gene expression profiling. Adv Immunol. 2005;87: $163-208$

141. Jacobson JO, Aisenberg AC, Lamarre L, et al. Mediastinal large cell lymphoma. An uncommon subset of adult lymphoma curable with combined modality therapy. Cancer. 1988;62(9): 1893-1898.

142. Hamlin PA, Portlock CS, Straus DJ, et al. Primary mediastinal large B-cell lymphoma: optimal therapy and prognostic factor analysis in 141 consecutive patients treated at Memorial Sloan Kettering from 1980 to 1999. Br J Haematol. 2005;130(5):691-699.

143. Todeschini G, Secchi S, Morra E, et al. Primary mediastinal large B-cell lymphoma (PMLBCL): long-term results from a retrospective multicentre Italian experience in 138 patients treated with CHOP or MACOP-B/VACOP-B. Br J Cancer. 2004;90(2):372-376.

144. van Besien K, Kelta M, Bahaguna P. Primary mediastinal B-cell lymphoma: a review of pathology and management. J Clin Oncol. 2001;19(6):1855-1864.

145. Moskowitz C, Hamlin PA Jr, Maragulia J, Meikle J, Zelenetz AD. Sequential dose-dense RCHOP followed by ICE vonsolidation (MSKCC protocol 01-142) without radiotherapy for patients with primary mediastinal large B cell lymphoma. ASH Annual Meeting Abstracts. 2010;116(21):420.
146. Shenkier TN, Blay JY, O’Neill BP, et al. Primary CNS lymphoma of T-cell origin: a descriptive analysis from the international primary CNS lymphoma collaborative group. J Clin Oncol. 2005;23(10):2233-2239.

147. Ferreri AJ. How I treat primary CNS lymphoma. Blood. 2011;118(3): 510-522.

148. Ferreri AJM, Blay J-Y, Reni M, et al. Prognostic scoring system for primary CNS lymphomas: the International Extranodal Lymphoma Study Group Experience. J Clin Oncol. 2003;21(2):266-272.

149. Illerhaus G, Marks R, Ihorst G, et al. High-dose chemotherapy with autologous stem-cell transplantation and hyperfractionated radiotherapy as first-line treatment of primary CNS lymphoma. J Clin Oncol. 2006;24(24):3865-3870.

150. Ponzoni M, Ferreri AJ, Campo E, et al. Definition, diagnosis, and management of intravascular large B-cell lymphoma: proposals and perspectives from an international consensus meeting. J Clin Oncol. 2007;25(21):3168-3173.

151. Murase T, Yamaguchi M, Suzuki R, et al. Intravascular large B-cell lymphoma (IVLBCL): a clinicopathologic study of 96 cases with special reference to the immunophenotypic heterogeneity of CD5. Blood. 2007;109(2):478-485.

152. Wahlin BE, Yri OE, Kimby E, et al. Clinical significance of the WHO grades of follicular lymphoma in a population-based cohort of 505 patients with long follow-up times. Br J Haematol. 2012;156(2): 225-233.

153. Trotman J, Fournier M, Lamy T, et al. Positron emission tomographycomputed tomography (PET-CT) after induction therapy is highly predictive of patient outcome in follicular lymphoma: analysis of PET-CT in a subset of PRIMA trial participants. J Clin Oncol. 2011;29(23):3194-3200.

154. Lopez-Guillermo A, Cabanillas F, McLaughlin P, et al. The clinical significance of molecular response in indolent follicular lymphomas. Blood. 1998;91(8):2955-2960.

155. Wilder RB, Jones D, Tucker SL, et al. Long-term results with radiotherapy for Stage I-II follicular lymphomas. Int J Radiat Oncol Biol Phys. 2001;51(5):1219-1227.

156. Richards MA, Gregory WM, Hall PA, et al. Management of localized non-Hodgkin's lymphoma: the experience at St. Bartholomew's Hospital 1972-1985. Hematol Oncol. 1989;7(1):1-18.

157. MacManus MP, Hoppe RT. Is radiotherapy curative for stage I and II low-grade follicular lymphoma? Results of a long-term follow-up study of patients treated at Stanford University. J Clin Oncol. 1996;14(4):1282-1290.

158. Solal-Celigny P, Lepage E, Brousse N, et al. Doxorubicin-containing regimen with or without interferon alfa-2b for advanced follicular lymphomas: final analysis of survival and toxicity in the Groupe d'Etude des Lymphomes Folliculaires 86 Trial. J Clin Oncol. 1998;16(7):2332-2338.

159. Horning SJ, Rosenberg SA. The natural history of initially untreated low-grade non-Hodgkin's lymphomas. $N$ Engl J Med. 1984;311(23):1471-1475.

160. Ardeshna KM, Qian W, Smith $P$, et al. An Intergroup randomised trial of rituximab versus a watch and wait strategy in patients with Stage II, III, IV, asymptomatic, non-bulky follicular lymphoma (grades 1, 2 and 3a). A preliminary analysis. ASH Annual Meeting Abstracts. 2010;116(21):6.

161. Rummel MJ, Niederle N, Maschmeyer G, et al. Bendamustine plus rituximab is superior in respect of progression free survival and CR rate when compared to $\mathrm{CHOP}$ plus rituximab as first-line treatment of patients with advanced follicular, indolent, and mantle cell lymphomas: Final results of a randomized Phase III study of the StiL (Study Group Indolent Lymphomas, Germany). ASH Annual Meeting Abstracts. 2009;114(22):405.

162. Deconinck E, Foussard C, Milpied N, et al. High-dose therapy followed by autologous purged stem-cell transplantation and doxorubicin-based chemotherapy in patients with advanced follicular lymphoma: a randomized multicenter study by GOELAMS. Blood. 2005;105(10):3817-3823. 
163. Peters A, Russell JA, Daly A, et al. Autologous stem cell transplantation is a curative treatment modality for relapsed or refractory follicular lymphoma, and both recent rituximab exposure and follicular lymphoma international prognostic index (FLIPI) 0-1 scores predict improved outcome. ASH Annual Meeting Abstracts. 2010;116(21):687.

164. Le Gouill S, De Guibert S, Planche L, et al. Impact of the use of autologous stem cell transplantation at first relapse both in naïve and previously rituximab exposed follicular lymphoma patients treated in the GELA/GOELAMS FL2000study. Haematologica. 2011;96(8):1128-1135

165. Gyan E, Foussard C, Bertrand P, et al. High-dose therapy followed by autologous purged stem cell transplantation and doxorubicinbased chemotherapy in patients with advanced follicular lymphoma: a randomized multicenter study by the GOELAMS with final results after a median follow-up of 9 years. Blood. 2009;113(5): 995-1001.

166. Toze CL, Barnett MJ, Connors JM, et al. Long-term disease-free survival of patients with advanced follicular lymphoma after allogeneic bone marrow transplantation. Br J Haematol. 2004;127(3):311-321.

167. van Besien K, Loberiza FR Jr, Bajorunaite R, et al. Comparison of autologous and allogeneic hematopoietic stem cell transplantation for follicular lymphoma. Blood. 2003;102(10):3521-3529.

168. Salles G, Seymour JF, Offner F, et al. Rituximab maintenance for 2 years in patients with high tumour burden follicular lymphoma responding to rituximab plus chemotherapy (PRIMA): a phase 3, randomised controlled trial. Lancet. 2011;377(9759):42-51.

169. Vidal L, Gafter-Gvili A, Salles G, et al. Rituximab maintenance for the treatment of patients with follicular lymphoma: an updated systematic review and meta-analysis of randomized trials. J Natl Cancer Inst. 2011;103(23):1799-1806.

170. Kaminski MS, Tuck M, Estes J, et al. 131I-tositumomab therapy as initial treatment for follicular lymphoma. NEngl J Med. 2005;352(5): 441-449.

171. Kaminski MS, Zelenetz AD, Press OW, et al. Pivotal study of iodine I 131 tositumomab for chemotherapy-refractory low-grade or transformed low-grade B-cell non-Hodgkin's lymphomas. J Clin Oncol. 2001;19(19):3918-3928.

172. Morschhauser F, Radford J, Van Hoof A, et al. Phase III trial of consolidation therapy with yttrium-90-ibritumomab tiuxetan compared with no additional therapy after first remission in advanced follicular lymphoma. J Clin Oncol. 2008;26(32):5156-5164.

173. Piris MA, Arribas A, Mollejo M. Marginal zone lymphoma. Semin Diagn Pathol. 2011;28(2):135-145.

174. Pich A, Fraire F, Fornari A, et al. Intrasinusoidal bone marrow infiltration and splenic marginal zone lymphoma: a quantitative study. Eur J Haematol. 2006;76(5):392-398.

175. Chacon JI, Mollejo M, Munoz E, et al. Splenic marginal zone lymphoma: clinical characteristics and prognostic factors in a series of 60 patients. Blood. 2002;100(5):1648-1654.

176. Saadoun D, Suarez F, Lefrere F, et al. Splenic lymphoma with villous lymphocytes, associated with type II cryoglobulinemia and HCV infection: a new entity? Blood. 2005;105(1):74-76.

177. Saadoun D, Sellam J, Ghillani-Dalbin P, Crecel R, Piette JC, Cacoub P Increased risks of lymphoma and death among patients with nonhepatitis C virus-related mixed cryoglobulinemia. Arch Intern Med. 2006;166(19):2101-2108.

178. Hermine O, Lefrere F, Bronowicki JP, et al. Regression of splenic lymphoma with villous lymphocytes after treatment of hepatitis $\mathrm{C}$ virus infection. $N$ Engl J Med. 2002;347(2):89-94.

179. Ohsawa M, Shingu N, Miwa H, et al. Risk of non-Hodgkin's lymphoma in patients with hepatitis $\mathrm{C}$ virus infection. Int $J$ Cancer. 1999;80(2):237-239.

180. Parry-Jones N, Matutes E, Gruszka-Westwood AM, Swansbury GJ, Wotherspoon AC, Catovsky D. Prognostic features of splenic lymphoma with villous lymphocytes: a report on 129 patients. $\mathrm{Br} J$ Haematol. 2003;120(5):759-764.
181. Bennett M, Schechter GP. Treatment of splenic marginal zone lymphoma: splenectomy versus rituximab. Semin Hematol. 2010;47(2):143-147.

182. Wundisch T, Thiede C, Morgner A, et al. Long-term follow-up of gastric MALT lymphoma after Helicobacter pylori eradication. J Clin Oncol. 2005;23(31):8018-8024.

183. Yeh KH, Kuo SH, Chen LT, et al. Nuclear expression of BCL10 or nuclear factor kappa B helps predict Helicobacter pyloriindependent status of low-grade gastric mucosa-associated lymphoid tissue lymphomas with or without $\mathrm{t}(11 ; 18)(\mathrm{q} 21 ; \mathrm{q} 21)$. Blood. 2005; 106(3):1037-1041.

184. Tsang RW, Gospodarowicz MK, Pintilie M, et al. Stage I and II MALT lymphoma: results of treatment with radiotherapy. Int J Radiat Oncol Biol Phys. 2001;50(5):1258-1264.

185. Fung CY, Grossbard ML, Linggood RM, et al. Mucosa-associated lymphoid tissue lymphoma of the stomach: long term outcome after local treatment. Cancer. 1999;85(1):9-17.

186. Ruskone-Fourmestraux A, Fischbach W, Aleman BM, et al. EGILS consensus report. Gastric extranodal marginal zone B-cell lymphoma of MALT. Gut. 2011;60(6):747-758.

187. Matasar MJ, Ritchie EK, Consedine N, Magai C, Neugut AI. Incidence rates of the major leukemia subtypes among US Hispanics, Blacks, and non-Hispanic Whites. Leuk Lymphoma. 2006;47(11):2365-2370.

188. Rai KR, Sawitsky A, Cronkite EP, Chanana AD, Levy RN, Pasternack BS Clinical staging of chronic lymphocytic leukemia. Blood. 1975;46(2): 219-234.

189. Binet JL, Auquier A, Dighiero G, et al. A new prognostic classification of chronic lymphocytic leukemia derived from a multivariate survival analysis. Cancer. 1981;48(1):198-206.

190. Shanafelt T, Hanson CA. Monoclonal B-cell lymphocytosis: definitions and natural history. Leuk Lymphoma. 2009;50(3):493-497.

191. Rawstron AC, Bennett FL, O’Connor SJ, et al. Monoclonal B-cell lymphocytosis and chronic lymphocytic leukemia. $N$ Engl J Med. 2008;359(6):575-583.

192. Eichhorst BF, Fischer K, Fink A-M, et al. Limited clinical relevance of imaging techniques in the follow-up of patients with advanced chronic lymphocytic leukemia: results of a meta-analysis. Blood. 2011;117(6):1817-1821.

193. Gribben JG. How I treat CLL up front. Blood. 2010;115(2):187-197.

194. Dohner H, Stilgenbauer S, Benner A, et al. Genomic aberrations and survival in chronic lymphocytic leukemia. $N$ Engl J Med. 2000;343(26):1910-1916.

195. Hamblin TJ, Davis Z, Gardiner A, Oscier DG, Stevenson FK. Unmutated $\mathrm{Ig} \mathrm{V}(\mathrm{H})$ genes are associated with a more aggressive form of chronic lymphocytic leukemia. Blood. 1999;94(6):1848-1854.

196. Dighiero G, Maloum K, Desablens B, et al. Chlorambucil in indolent chronic lymphocytic leukemia. French Cooperative Group on Chronic Lymphocytic Leukemia. N Engl J Med. 1998;338(21):1506-1514.

197. Hallek M, Fischer K, Fingerle-Rowson G, et al. Addition of rituximab to fludarabine and cyclophosphamide in patients with chronic lymphocytic leukaemia: a randomised, open-label, phase 3 trial. Lancet. 2010;376(9747):1164-1174.

198. Woyach JA, Ruppert AS, Heerema NA, et al. Chemoimmunotherapy with fludarabine and rituximab produces extended overall survival and progression-free survival in chronic lymphocytic leukemia: long-term follow-up of CALGB study 9712. J Clin Oncol. 2011;29(10):1349-1355.

199. Zenz T, Eichhorst B, Busch R, et al. TP53 mutation and survival in chronic lymphocytic leukemia. J Clin Oncol. 2010;28(29):4473-4479.

200. Stilgenbauer S, Zenz T, Winkler D, et al. Subcutaneous alemtuzumab in fludarabine-refractory chronic lymphocytic leukemia: clinical results and prognostic marker analyses from the CLL2H study of the German Chronic Lymphocytic Leukemia Study Group. J Clin Oncol. 2009;27(24):3994-4001

201. O'Brien SM, Kantarjian HM, Thomas DA, et al. Alemtuzumab as treatment for residual disease after chemotherapy in patients with chronic lymphocytic leukemia. Cancer. 2003;98(12):2657-2663. 
202. Knauf WU, Lissichkov T, Aldaoud A, et al. Phase III randomized study of bendamustine compared with chlorambucil in previously untreated patients with chronic lymphocytic leukemia. J Clin Oncol. 2009;27(26):4378-4384.

203. Fischer K, Cramer P, Busch R, et al. Bendamustine combined with rituximab in patients with relapsed and/or refractory chronic lymphocytic leukemia: a multicenter Phase II trial of the German Chronic Lymphocytic Leukemia Study Group. J Clin Oncol. 2011;29(26):3559-3566.

204. Wierda WG, Kipps TJ, Mayer J, et al. Ofatumumab as single-agent CD20 immunotherapy in fludarabine-refractory chronic lymphocytic leukemia. J Clin Oncol. 2010;28(10):1749-1755.

205. Wierda WG, Padmanabhan S, Chan GW, et al. Ofatumumab is active in patients with fludarabine-refractory CLL irrespective of prior rituximab: results from the phase 2 international study. Blood. 2011;118(19):5126-5129.

206. Tsimberidou AM, Keating MJ. Richter syndrome: biology, incidence, and therapeutic strategies. Cancer. 2005;103(2):216-228.

207. Cohen PL, Kurtin PJ, Donovan KA, Hanson CA. Bone marrow and peripheral blood involvement in mantle cell lymphoma. Br J Haematol. 1998;101(2):302-310.

208. Raty R, Franssila K, Jansson SE, Joensuu H, Wartiovaara-Kautto U, Elonen E. Predictive factors for blastoid transformation in the common variant of mantle cell lymphoma. Eur J Cancer. 2003;39(3):321-329.

209. Bodet-Milin C, Touzeau C, Leux C, et al. Prognostic impact of 18Ffluoro-deoxyglucose positron emission tomography in untreated mantle cell lymphoma: a retrospective study from the GOELAMS group. Eur J Nucl Med Mol Imaging. 2010;37(9):1633-1642.

210. Schaffel R, Hedvat CV, Teruya-Feldstein J, et al. Prognostic impact of proliferative index determined by quantitative image analysis and the International Prognostic Index in patients with mantle cell lymphoma. Ann Oncol. 2010;21(1):133-139.

211. Martin P, ChadburnA, Christos P, et al. Outcome of deferred initial therapy in mantle-cell lymphoma. J Clin Oncol. 2009;27(8):1209-1213.

212. Ondrejka SL, Lai R, Smith SD, Hsi ED. Indolent mantle cell leukemia: a clinicopathological variant characterized by isolated lymphocytosis, interstitial bone marrow involvement, kappa light chain restriction, and good prognosis. Haematologica. 2011;96(8):1121-1127.

213. Orchard J, Garand R, Davis Z, et al. A subset of $\mathrm{t}(11 ; 14)$ lymphoma with mantle cell features displays mutated IgVH genes and includes patients with good prognosis, nonnodal disease. Blood. 2003;101(12):4975-4981.

214. Lenz G, Dreyling M, Hoster E, etal. Immunochemotherapy with rituximab and cyclophosphamide, doxorubicin, vincristine, and prednisone significantly improves response and time to treatment failure, but not long-term outcome in patients with previously untreated mantle cell lymphoma: results of a prospective randomized trial of the German Low Grade Lymphoma Study Group (GLSG). J Clin Oncol. 2005;23(9):1984-1992.

215. Geisler CH, Kolstad A, Laurell A, et al. Long-term progression-free survival of mantle cell lymphoma after intensive front-line immunochemotherapy with in vivo-purged stem cell rescue: a nonrandomized phase 2 multicenter study by the Nordic Lymphoma Group. Blood. 2008;112(7):2687-2693.

216. Rummel MJ, Al-Batran SE, Kim SZ, et al. Bendamustine plus rituximab is effective and has a favorable toxicity profile in the treatment of mantle cell and low-grade non-Hodgkin's lymphoma. J Clin Oncol. 2005;23(15):3383-3389.

217. Fisher RI, Bernstein SH, Kahl BS, et al. Multicenter phase II study of bortezomib in patients with relapsed or refractory mantle cell lymphoma. J Clin Oncol. 2006;24(30):4867-4874.

218. Hess G, Herbrecht R, Romaguera J, et al. Phase III study to evaluate temsirolimus compared with investigator's choice therapy for the treatment of relapsed or refractory mantle cell lymphoma. J Clin Oncol. 2009;27(23):3822-3829.
219. Vose JM. Burkitt lymphoma. In: O’Brien S, Vose JM, Kantarjian HM, editors. Management of Hematologic Malignancies. Cambridge, UK: Cambridge University Press; 2011.

220. Lim ST, Karim R, Nathwani BN, Tulpule A, Espina B, Levine AM. AIDS-related Burkitt's lymphoma versus diffuse large-cell lymphoma in the pre-highly active antiretroviral therapy (HAART) and HAART eras: significant differences in survival with standard chemotherapy. $J$ Clin Oncol. 2005;23(19):4430-4438.

221. Mead GM, Sydes MR, Walewski J, et al. An international evaluation of CODOX-M and CODOX-M alternating with IVAC in adult Burkitt's lymphoma: results of United Kingdom Lymphoma Group LY06 study. Ann Oncol. 2002;13(8):1264-1274.

222. Thomas DA, Cortes J, O'Brien S, et al. Hyper-CVAD program in Burkitt's-type adult acute lymphoblastic leukemia. J Clin Oncol. 1999;17(8):2461-2470.

223. Rizzieri DA, Johnson JL, Niedzwiecki D, et al. Intensive chemotherapy with and without cranial radiation for Burkitt leukemia and lymphoma: final results of Cancer and Leukemia Group B Study 9251. Cancer. 2004;100(7):1438-1448.

224. Thomas DA, Faderl S, O'Brien S, et al. Chemoimmunotherapy with hyper-CVAD plus rituximab for the treatment of adult Burkitt and Burkitt-type lymphoma or acute lymphoblastic leukemia. Cancer. 2006;106(7):1569-1580.

225. Kaplan LD, Lee JY, Ambinder RF, et al. Rituximab does not improve clinical outcome in a randomized phase 3 trial of CHOP with or without rituximab in patients with HIV-associated non-Hodgkin lymphoma: AIDS-Malignancies Consortium Trial 010. Blood. 2005;106(5):1538-1543.

226. Rudiger T, Weisenburger DD, Anderson JR, et al. Peripheral T-cell lymphoma (excluding anaplastic large-cell lymphoma): results from the non-Hodgkin's Lymphoma Classification Project. Ann Oncol. 2002;13(1):140-149.

227. Weisenburger DD, Savage KJ, Harris NL, et al. Peripheral T-cell lymphoma, not otherwise specified: a report of 340 cases from the International Peripheral T-cell Lymphoma Project. Blood. 2011;117(12): 3402-3408.

228. Foss FM, Zinzani PL, Vose JM, Gascoyne RD, Rosen ST, Tobinai K. Peripheral T-cell lymphoma. Blood. 2011;117(25):6756-6767.

229. Tilly H, Lepage E, Coiffier B, et al. Intensive conventional chemotherapy (ACVBP regimen) compared with standard CHOP for poor-prognosis aggressive non-Hodgkin lymphoma. Blood. 2003;102(13):4284-4289.

230. O'Connor OA, Pro B, Pinter-Brown L, et al. Pralatrexate in patients with relapsed or refractory peripheral T-cell lymphoma: results from the pivotal PROPEL study. J Clin Oncol. 2011;29(9): 1182-1189.

231. de Leval L, Rickman DS, Thielen C, et al. The gene expression profile of nodal peripheral T-cell lymphoma demonstrates a molecular link between angioimmunoblastic T-cell lymphoma (AITL) and follicular helper T (TFH) cells. Blood. 2007;109(11): 4952-4963.

232. Vose J, Armitage J, Weisenburger D. International peripheral T-cell and natural killer/T-cell lymphoma study: pathology findings and clinical outcomes. J Clin Oncol. 2008;26(25):4124-4130.

233. AbouYabis AN, Shenoy PJ, Flowers C, Lechowicz MJ. Response and survival rates in patients with peripheral T-cell lymphoma treated with anthracycline-based regimens: a comprehensive meta-analysis. $A S H$ Annual Meeting Abstracts. 2007;110(11):3452.

234. Vose JM; The International PTCL Project. International Peripheral T-Cell Lymphoma (PTCL) clinical and pathologic review project: poor outcome by prognostic indices and lack of efficacy with anthracyclines. ASH Annual Meeting Abstracts. 2005;106(11):811.

235. Rodriguez J, Conde E, Gutierrez A, et al. Frontline autologous stem cell transplantation in high-risk peripheral T-cell lymphoma: a prospective study from The Gel-Tamo Study Group. Eur J Haematol. 2007;79(1):32-38. 
236. Schetelig J, Fetscher S, Reichle A, et al. Long-term disease-free survival in patients with angioimmunoblastic T-cell lymphoma after high-dose chemotherapy and autologous stem cell transplantation. Haematologica. 2003;88(11):1272-1278.

237. Kyriakou C, Canals C, Goldstone A, et al. High-dose therapy and autologous stem-cell transplantation in angioimmunoblastic lymphoma: complete remission at transplantation is the major determinant of Outcome-Lymphoma Working Party of the European Group for Blood and Marrow Transplantation. J Clin Oncol. 2008;26(2):218-224.

238. Morris SW, Kirstein MN, Valentine MB, et al. Fusion of a kinase gene, ALK, to a nucleolar protein gene, NPM, in non-Hodgkin's lymphoma. Science. 1995;267(5196):316-317.
239. Falini B, Pileri S, Zinzani PL, et al. ALK+ lymphoma: clinicopathological findings and outcome. Blood. 1999;93(8):2697-2706.

240. Gascoyne RD, Aoun P, Wu D, et al. Prognostic significance of anaplastic lymphoma kinase (ALK) protein expression in adults with anaplastic large cell lymphoma. Blood. 1999;93(11):3913-3921.

241. Campo E, Swerdlow SH, Harris NL, Pileri S, Stein H, Jaffe ES. The 2008 WHO classification of lymphoid neoplasms and beyond: evolving concepts and practical applications. Blood. 2011;117(19):5019-5032.

242. Armitage JO. Early-stage Hodgkin's lymphoma. $N$ Engl J Med. 2010;363(7):653-662.

\section{Publish your work in this journal}

Blood and Lymphatic Cancer: Targets and Therapy is an international, peer-reviewed, open access journal focusing on blood and lymphatic cancer research, identification of therapeutic targets and the optimal use of preventative and integrated treatment interventions to achieve improved outcomes, enhanced survival and quality of life for the cancer patient. The manuscript management system is completely online and includes a very quick and fair peer-review system. Visit http://www.dovepress.com/testimonials.php to read real quotes from published authors.

Submit your manuscript here: http://www.dovepress.com/blood-and-lymphatic-cancer-targets-and-therapy-journal 